\title{
Impacto del COVID-19 en la economía de los Estados Unidos y respuestas de política
}

\section{Introducción}

La pandemia de enfermedad por coronavirus (COVID-19) ha cambiado drásticamente la economía mundial y la de los Estados Unidos, cobrándose una gran cantidad de víctimas y provocando el cierre de importantes sectores económicos. Si bien existe una gran incertidumbre respecto de las perspectivas de crecimiento económico de los Estados Unidos, el impacto de la pandemia es duro. La expansión económica récord de los Estados Unidos llegó a su fin a causa del COVID-19, con pronósticos de una profunda recesión en 2020. Las perspectivas continúan siendo muy inciertas, ya que resulta difícil estimar las repercusiones sociales y económicas de la pandemia, que dependerán del éxito en la contención del brote y de las medidas adoptadas para reiniciar la actividad económica.

La respuesta de política económica a la pandemia de COVID-19 ha sido inmediata y muy amplia. En marzo, el Congreso de los Estados Unidos aprobó tres paquetes de estímulo con el fin de contener el impacto en los hogares y las empresas. En abril y junio se aprobaron nuevas leyes para mejorar la eficacia de los programas incluidos en los tres paquetes fiscales mencionados. La Reserva Federal redujo las tasas de interés hasta el límite inferior de cero, ofreció una expansión cuantitativa ilimitada y recurrió a distintos instrumentos de política —unos que ya existían y otros nuevos - para mantener en funcionamiento los mercados financieros.

\section{La expansión económica récord de los Estados Unidos llega a su fin ${ }^{1}$}

En 2020 se prevé que se produzca una gran recesión debido a los efectos de la pandemia. Las proyecciones medianas de la Reserva Federal del 10 de junio indican que en 2020 se registrará una disminución del 6,5\% del PIB (con proyecciones que van del -10\% al -4,2\%), lo que supone una contracción mucho mayor que la anotada en 2009 (-2,5\%). La pandemia vino a interrumpir más de una década de crecimiento económico (128 meses consecutivos, de junio de 2009 a febrero de 2020), en la que, pese a ser menos robusta que los ciclos anteriores, fue la expansión más larga jamás registrada en los Estados Unidos (véase el gráfico 1)².

La información empleada para la elaboración de este documento, salvo que se indique otra cosa, es la disponible hasta el 29 de julio de 2020

El 8 de junio de 2020, el Comité de Datación del Ciclo Económico de la Oficina Nacional de Investigaciones Económicas, que lleva una cronología de los máximos y mínimos de los ciclos económicos de los Estados Unidos, determinó que en febrero de 2020 se alcanzó un máximo en la actividad económica mensual de los Estados Unidos, momento que se señala como el final oficial de la expansión (NBER, 2020).

\section{Introducción}

I. La expansión económica récord de los Estados Unidos llega a su fin

II. Colapso del empleo

III. Desplome de la producción industrial y las ventas al por menor

IV. Fuertes y rápidas repercusiones en los mercados financieros

v. Disrupción de los flujos comerciales y las cadenas de suministro

VI. Fuerte impacto en la migración

VII. La respuesta de política económica de los Estados Unidos: rápida y contundente

VIII. Desafíos a largo plazo Bibliografía
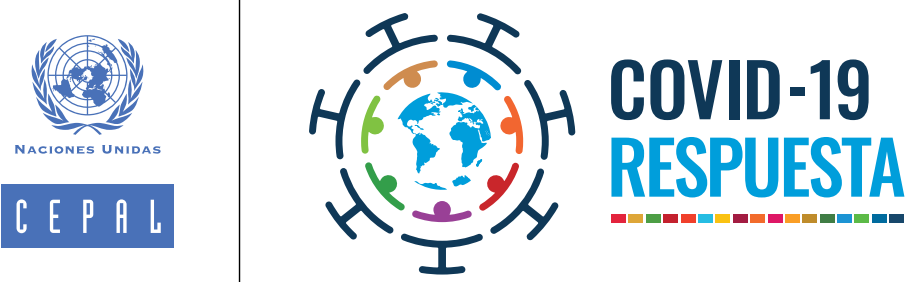


\section{Gráfico 1}

Estados Unidos: expansiones económicas, períodos seleccionados entre febrero de 1961 y febrero de 2020

(En cantidad de meses y en porcentajes del PIB)

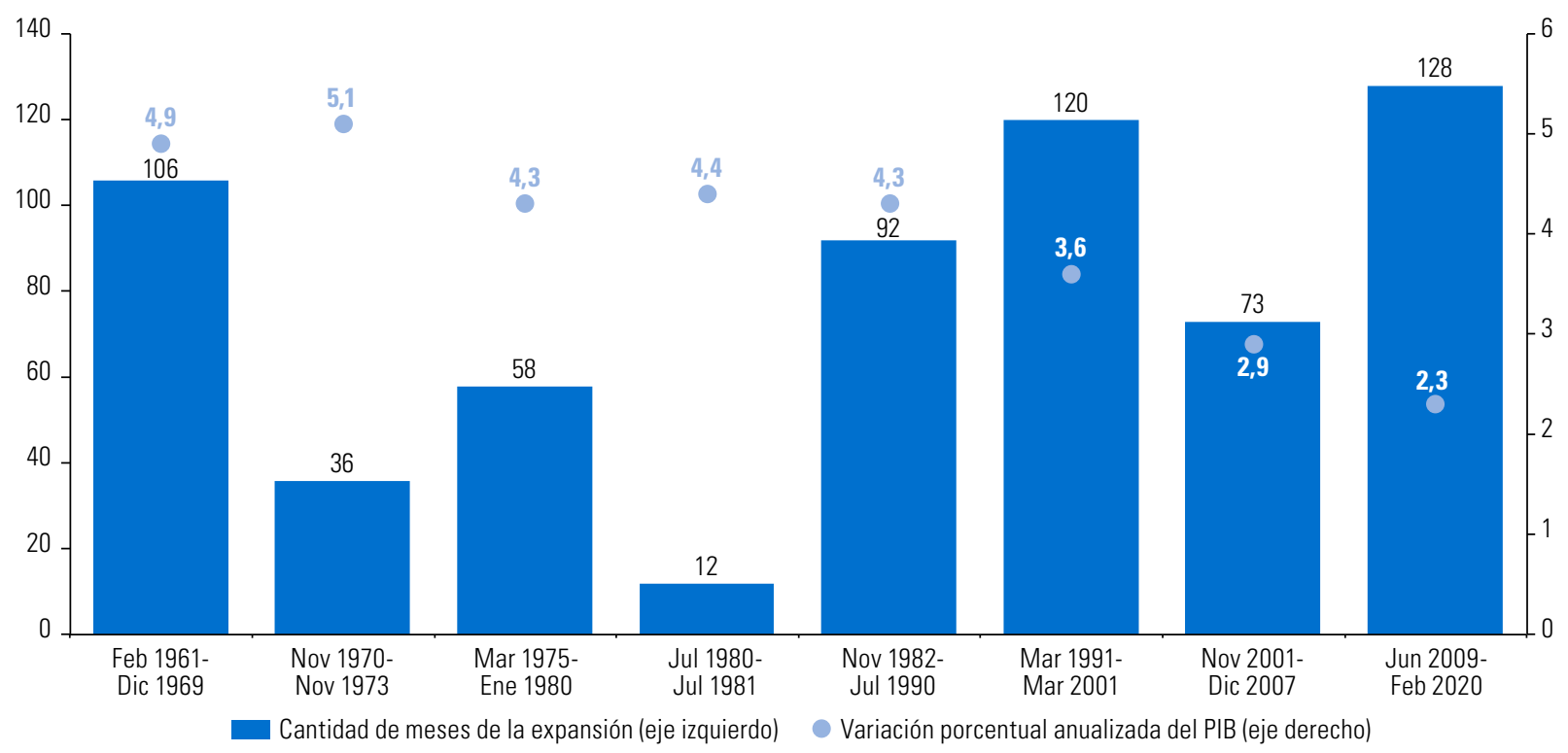

Fuente: Comisión Económica para América Latina y el Caribe (CEPAL), sobre la base de datos de la Oficina Nacional de Investigaciones Económicas (NBER) y la Oficina de Análisis Económico del Departamento de Comercio de los Estados Unidos.

Los efectos del COVID-19 y de las medidas de contención ya eran visibles en la estimación final para el primer trimestre de 2020 (una contracción del 5\%), así como en las cifras de empleo y producción fabril. La estimación anticipada del crecimiento del PIB en el segundo trimestre muestra una contracción del 32,9\%. La pandemia ha provocado quiebras de empresas, un descenso de la inversión privada, una menor integración en las cadenas de valor y una erosión de las capacidades productivas y el capital humano. La duración e intensidad de la caída económica es incierta, y se desconoce si habrá daños duraderos y cómo será la recuperación una vez que se flexibilicen las medidas de contención.

\section{Colapso del empleo}

El colapso del empleo es de una magnitud sin precedentes y es probable que alcance 0 supere el de cualquier recesión ocurrida en los últimos 150 años (Rogoff, 2020). En las 18 semanas que van desde la semana que terminó el 21 de marzo hasta la semana que terminó el 18 de julio, 52,7 millones de personas solicitaron beneficios del seguro de desempleo, lo que supera el récord anterior. Si bien las nuevas solicitudes de prestaciones por desempleo han disminuido desde que los cierres relacionados con la pandemia condujeron a un nivel máximo a fines de marzo, seguían ubicándose en torno a 1,5 millones por semana al final de la tercera semana de julio (véase el gráfico 2). Las solicitudes de subsidio por desempleo se estabilizaron en junio y en las dos primeras semanas de julio, lo que indica que los nuevos despidos se fueron compensando, en gran medida, con la contratación y recontratación de trabajadores por parte de las empresas, a medida que los estados fueron reabriendo sus economías. No obstante, el desempleo se mantiene en niveles históricamente altos ${ }^{3}$.

Las prestaciones por desempleo se han extendido a algunas personas que antes no tenían derecho a esa ayuda, como los trabajadores por cuenta propia y los que se desempeñan en la economía de los pequeños encargos (la llamada gig economy). Según el Departamento del Trabajo, alrededor de 10 millones de trabajadores, que se contabilizan por separado respecto del programa regular de seguro de desempleo, recibían esas prestaciones a fines de mayo. 


\section{Gráfico 2}

Estados Unidos: solicitudes iniciales de subsidio por desempleo presentadas semanalmente,

21 de diciembre de 2019 a 18 de julio de 2020

(En número de solicitudes)

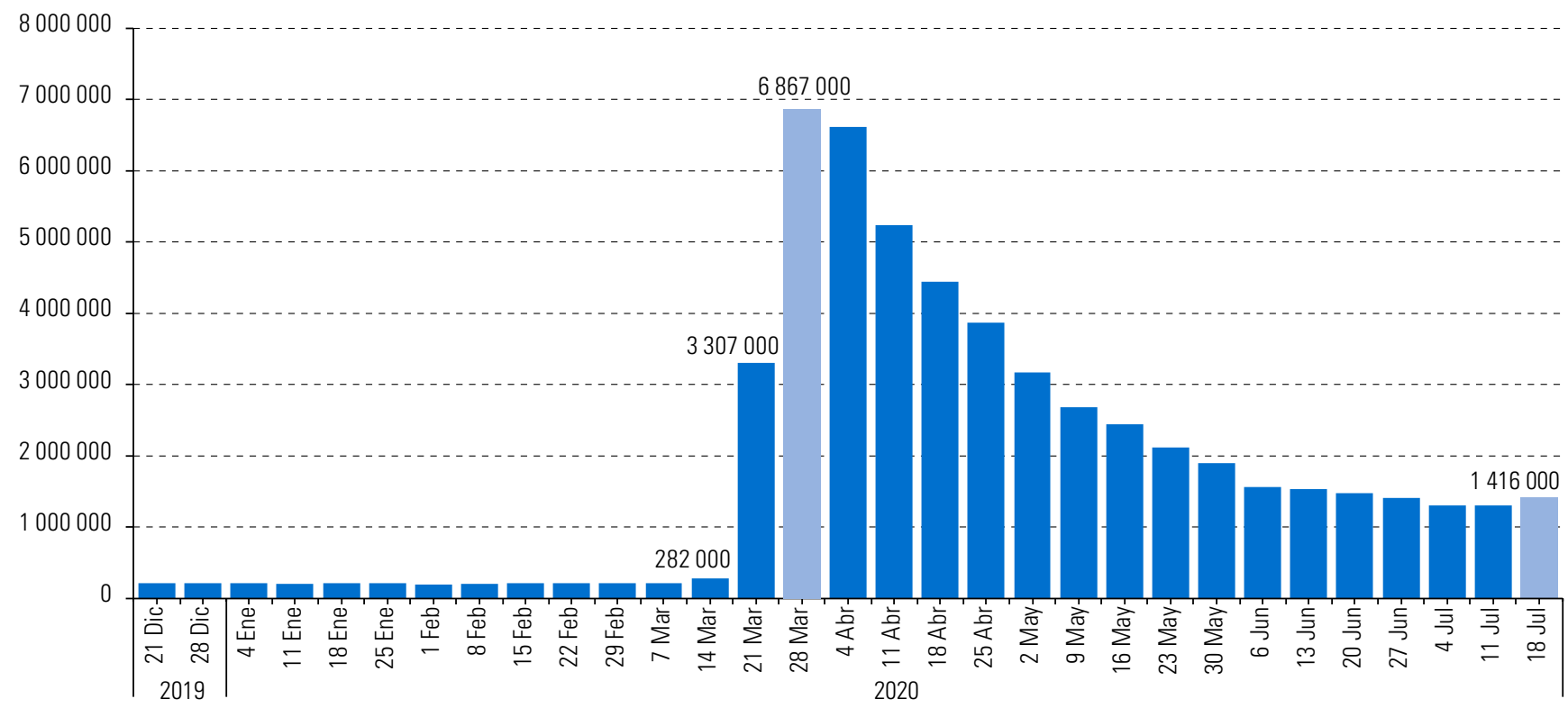

Fuente: Comisión Económica para América Latina y el Caribe (CEPAL), sobre la base de Departamento del Trabajo de los Estados Unidos, "Unemployment insurance weekly claims report" [en línea] https://fred.stlouisfed.org/series/ICSA, y datos del Banco de la Reserva Federal de St. Louis.

El período más largo de creación de empleo en la historia de los Estados Unidos — 113 meses consecutivos - tuvo un final abrupto en marzo de 2020, cuando se perdieron 870.000 puestos de trabajo a causa de la pandemia. En abril, la economía estadounidense perdió cerca de 21 millones de puestos de trabajo, en lo que fue la mayor caída jamás registrada y duplicó con creces la pérdida acumulada durante la crisis financiera mundial de 2008-2009. La tasa de desempleo saltó al 14,7\%, del 4,4\% registrado en marzo y el 3,5\% de febrero, que había sido la más baja en 50 años (véase el gráfico 3).

\section{Gráfico 3}

Estados Unidos: creación de empleo y tasa de desempleo mensual promedio, enero a junio de 2020 (En millones de puestos de trabajo y porcentajes)

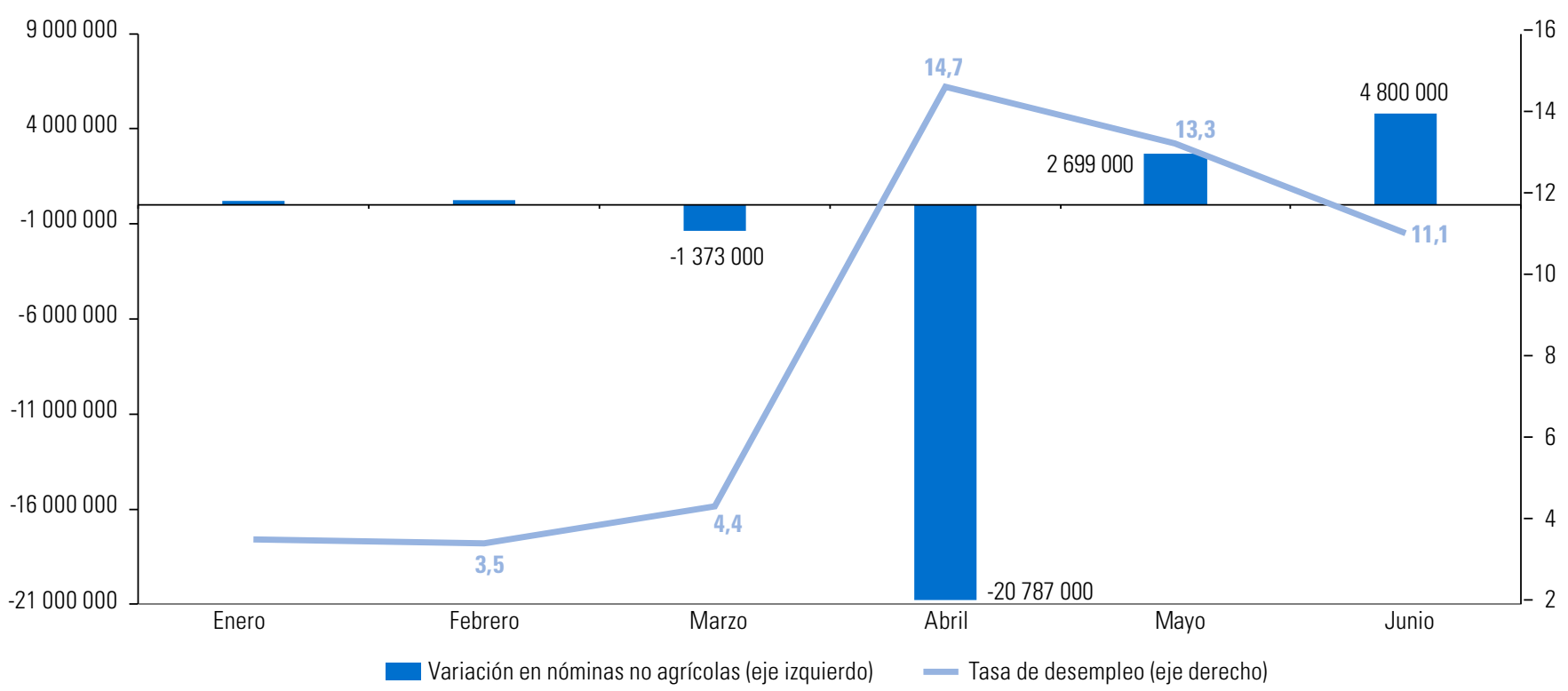

Fuente: Comisión Económica para América Latina y el Caribe (CEPAL), sobre la base de datos de la Oficina de Estadísticas Laborales de los Estados Unidos 
Los datos de desempleo indican que los hispanos, los afroamericanos y los trabajadores que perciben bajos salarios en los sectores de restaurantes y comercios minoristas han sido los más afectados. La tasa de desempleo en abril se disparó a cifras sin precedentes: un $18,9 \%$ para los hispanos, un $16,7 \%$ para los afroamericanos, un $14,5 \%$ para los asiáticos y un $14,2 \%$ para los blancos. Las mujeres registraron una tasa de desempleo más alta que los hombres en todos los grupos (BLS, 2020a).

Con la reapertura de la actividad económica de varios estados en mayo, cientos de miles de trabajadores volvieron a sus empleos en restaurantes, servicios de atención médica y construcción. Como consecuencia, en mayo se crearon unos 2,5 millones de puestos de trabajo y en junio se crearon otros 4,8 millones, dos aumentos que en parte también se debieron a la respuesta de política fiscal y el apoyo a las pequeñas empresas. La tasa de desempleo bajó al 13,3\% en mayo y al 11,1\% en junio ${ }^{4}$. En junio, la tasa de desempleo bajó al 16,1\% para los hispanos, al 14,5\% para los afroamericanos, al 13,8\% para los asiáticos y al 10,1\% para los blancos. En general, la tasa de desempleo de las mujeres continuó siendo más alta que la de los hombres (BLS, 2020b y 2020c).

La edad y la educación también son factores relevantes, ya que los trabajadores más jóvenes y los obreros, así como los que no cuentan con un título universitario, tienen más probabilidades de haber perdido el empleo. Las tasas de desempleo en abril y junio fueron del $21,2 \%$ y el $16,6 \%$, respectivamente, para los mayores de 25 años que no terminaron la secundaria, y del $8,4 \%$ y el 6,9\%, respectivamente, para los que tienen un título universitario o superior. En el caso de los trabajadores de entre 16 y 19 años, la tasa de desempleo fue del $31,9 \%$ en abril y del $23,2 \%$ en junio, frente a un $13,1 \%$ y un $9,7 \%$, respectivamente, para los de 25 años y más.

Al analizar los efectos de la pandemia por sectores, se observa que el sector de los servicios sufrió un impacto sin precedentes. Alrededor del 37,3\% de las pérdidas de puestos de trabajo en abril se registraron en los sectores de esparcimiento y hostelería, pero también hubo notables descensos en los de educación y servicios de salud (12,4\%), servicios profesionales y empresariales $(10,4 \%)$, y comercio al por menor $(10,3 \%)$ (véase el gráfico 4). Estos sectores sufrieron los efectos inmediatos y directos de las medidas de confinamiento y distanciamiento físico aplicadas por los estados en todo el país a causa de la pandemia, que incluyeron restricciones a los viajes, la prohibición de comer en los restaurantes y el cierre de bares y otros lugares de esparcimiento. Según datos de la Oficina de Estadísticas Laborales de los Estados Unidos, en conjunto, estos sectores representaban más del 31\% del valor agregado a la economía antes de la pandemia (BLS, 2020d). También hubo pérdidas de puestos de trabajo en el sector manufacturero (6,5\%), debido a que las medidas de confinamiento y las restricciones en las cadenas de suministro limitaron la producción fabril, y en la construcción (4,8\%).

En mayo y junio, los sectores de esparcimiento y hostelería, que habían sufrido las mayores pérdidas en marzo y abril, registraron los mayores aumentos del empleo. Más de la quinta parte de la población está empleada directamente en el comercio al por menor y la hostelería, lo que incluye tiendas, bares y restaurantes, y los sectores de turismo y entretenimiento. Esto significa que más de 32 millones de personas trabajan en sectores que se vieron afectados por la gran cantidad de cierres y despidos a causa de la pandemia de COVID-19. Las repercusiones han sido generalizadas, desde los hogares hasta las economías locales, pasando por los presupuestos municipales, ya que no se pagaron alquileres, salarios ni impuestos sobre las ventas.

En el comunicado de prensa de Situación del Empleo emitido por la Oficina de Estadísticas Laborales de los Estados Unidos (BLS, 2020b) para el mes de mayo se incluyó una nota extraordinaria que decía que si los trabajadores que se habían registrado como empleados pero habían estado ausentes del empleo por "otros motivos" (por encima de la cantidad de ausentes por otros motivos en un mes de mayo típico) se hubieran clasificado como desempleados con suspensión de empleo, la tasa de desempleo global habría sido unos 3 puntos porcentuales superior a la tasa oficial registrada del 13,3\%. Estos posibles errores también incidieron en los informes mensuales de marzo y abril, y reflejan las dificultades que plantea el impacto sin precedentes de la pandemia en el empleo. La tasa de desempleo de mayo, tanto oficial como corregida, no obstante, mostró una mejora con respecto a las cifras de abril. 
Gráfico 4

Estados Unidos: variación en el empleo por industria, abril, mayo y junio de 2020 (Cifras desestacionalizadas, en miles)

\section{A. Abril 2020}

Esparcimiento y hostelería

Educación y servicios de salud

Servicios profesionales y empresariales

Comercio al por menor

Manufacturas

Otros servicios

Construcción

Transporte y almacenamiento

Comercio al por mayor

Actividades financieras

Información

Explotación minera y forestal

Servicios públicos

Gobierno

\section{B. Mayo 2020}

Esparcimiento y hostelería

Construcción

Educación y servicios de salud

Comercio al por menor

Otros servicios

Manufacturas

Servicios profesionales y empresariales

Actividades financieras

Comercio al por mayor

Servicios públicos

Transporte y almacenamiento

Explotación minera y forestal

Información

Gobierno

\section{Junio 2020}

Esparcimiento y hostelería

Comercio al por menor

Educación y servicios de salud

Otros servicios

Manufacturas

Servicios profesionales y empresariales

Construcción

Transporte y almacenamiento

Comercio al por mayor

Actividades financieras

Información

Servicios públicos

Explotación minera y forestal

Gobierno

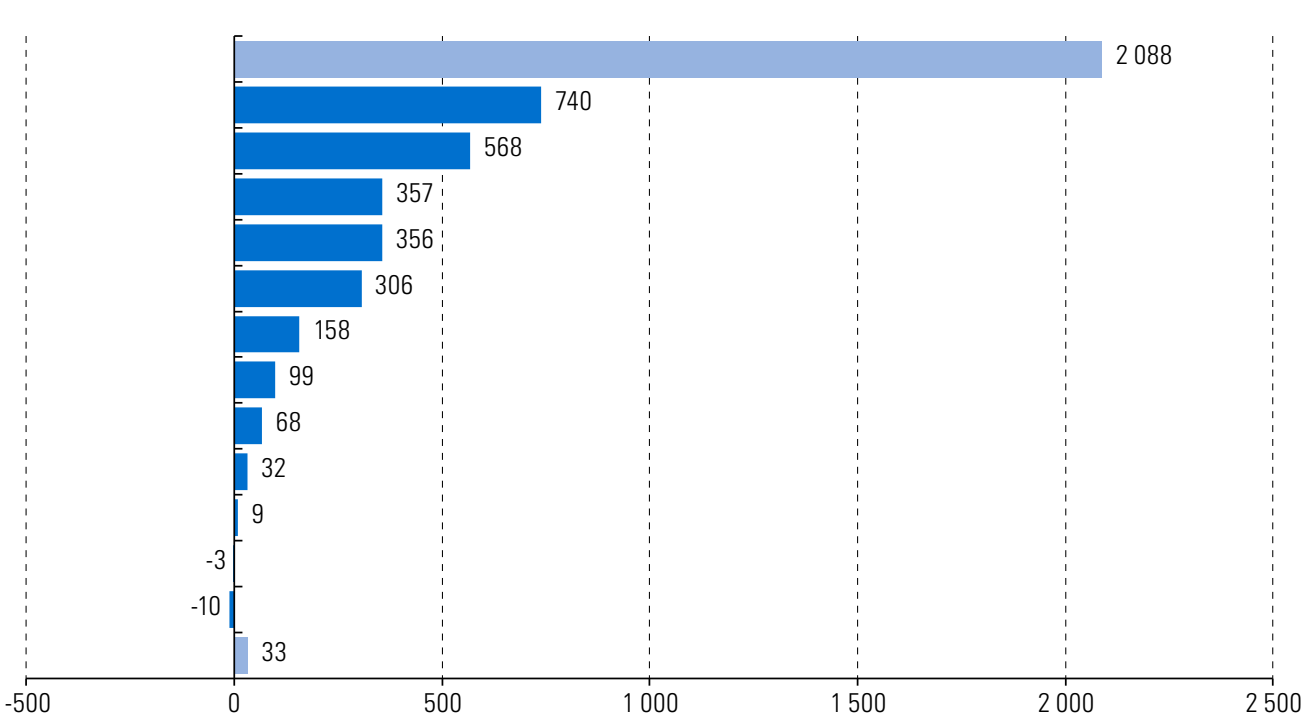

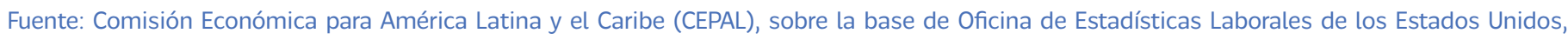

"Current Employment Statistics" [en línea] https://www.bls.gov/ces/. 
Los gobiernos estatales y locales eliminaron 980.000 puestos de trabajo en abril y 585.000 en mayo. Desde febrero, han recortado un total de 1,5 millones de puestos de trabajo, una caída del $8 \%$ que es el doble de la observada durante y después de la recesión de 2008-2009. El impacto de la pandemia en las economías estatales y locales, así como en los presupuestos municipales, es preocupante, tanto como intentar evitar un deterioro más permanente de las relaciones laborales entre empleadores y empleados tras las supresiones de puestos de trabajo en el sector privado. Esto puede requerir un apoyo extra por parte del Gobierno para abordar los problemas presupuestarios de los gobiernos estatales y locales provocados por la pandemia, y para ayudar a las empresas a conservar la mayor cantidad de empleados posible.

\section{Desplome de la producción industrial y las ventas al por menor}

La pandemia combina aspectos de choques tanto de la oferta como de la demanda (Brinca, Duarte y Faria e Castro, 2020). Mientras que las medidas de confinamiento han repercutido en la capacidad de la economía para producir bienes y servicios, la menor capacidad o disposición de los consumidores para adquirir bienes y servicios, en medio de los despidos laborales y el temor al contagio, ha debilitado la demanda.

Según los datos de la Junta de Gobernadores de la Reserva Federal (2020a), tras un descenso del 4,5\% en marzo, la producción industrial, que es un amplio indicador de la producción de las fábricas, las minas y los servicios públicos, bajó un 12,7\% desestacionalizado en abril, en lo que fue el descenso mensual más pronunciado después de la caída récord del 10,4\% verificada en agosto de 1945 (véase el gráfico 5). Tras dos meses consecutivos de contracción, la producción industrial aumentó un 1,4\% en mayo y un 5,4\% en junio. La producción manufacturera, el mayor componente de la producción industrial, se incrementó un 3,8\% en mayo, cuando muchas fábricas reanudaron sus operaciones, y pese a que también se elevó un 7,2\% en junio, aún seguía estando un 11,1\% por debajo del nivel previo a la pandemia.

Gráfico 5

Estados Unidos: variación mensual de la producción industrial, abril de 2015 a junio de 2020

(Variación porcentual desestacionalizada)

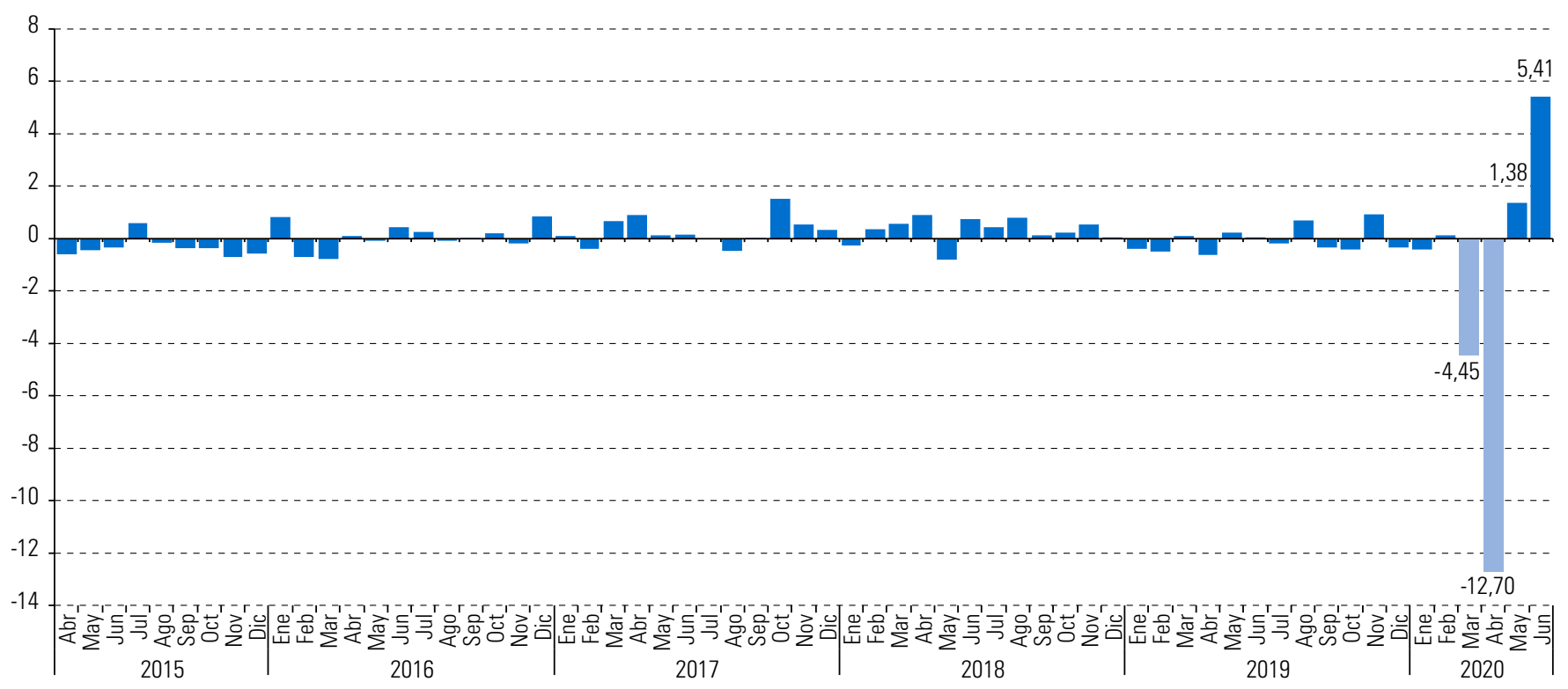

Fuente: Comisión Económica para América Latina y el Caribe (CEPAL), sobre la base de datos de la Reserva Federal de los Estados Unidos y del Banco de la Reserva Federal de St. Louis. 
Las cifras de la Oficina del Censo de los Estados Unidos (2020) indican que las ventas al por menor (una medida de las compras en tiendas, gasolineras, restaurantes, bares y en línea) registraron un descenso récord del 14,7\% en abril y del 8,2\% en marzo, lo que muestra cómo la pandemia reorientó y frenó los hábitos de consumo en los Estados Unidos. Estas fueron las mayores reducciones mensuales desde que se comenzó a llevar un registro en 1992. En mayo, sin embargo, las ventas al por menor lograron una recuperación sin precedentes del $18,2 \%$, desafiando las expectativas y revirtiendo con creces el descenso de abril. El aumento del gasto se produjo cuando 2,5 millones de empleados volvieron a trabajar y los ingresos de los hogares recibieron el complemento de la asistencia federal. Las ventas al por menor siguieron aumentando en junio y llegaron a registrar un alza del 7,5\%, pero eso fue sobre todo antes de que el aumento de las infecciones por COVID-19 llevara a los estados a detener o retroceder en el proceso de reapertura. A pesar de los aumentos, las ventas en junio seguían estando un 0,6\% abajo en comparación con el mes de febrero.

El hecho de que el sector privado ya estuviera muy endeudado antes de la pandemia lo hace aún más vulnerable a los efectos del COVID-19. A diferencia de la situación que se vivió durante la crisis financiera mundial de 2008-2009, en la actualidad la vulnerabilidad no radica principalmente en el sector financiero, sino en la gran cantidad de empresas sobreendeudadas que están viendo colapsar sus ingresos a causa del confinamiento provocado por la pandemia. El impacto de la pandemia en el mercado ha alimentado las expectativas de que aumenten las presentaciones de declaración de quiebra. Algunas grandes empresas que operan en los sectores minorista, de petróleo y gas, de esparcimiento y hostelería, y otros, entre las que se encuentran Hertz, Whiting Petroleum, Gold's Gym, Pier 1, J.Crew, JCPenney y Neiman Marcus, ya se han acogido a medidas de quiebra en virtud del capítulo 11 de la Ley de quiebras. Esto les permite negociar con los acreedores para reestructurar los términos de la deuda (las declaraciones en virtud del capítulo 7 por lo general implican la liquidación de los activos y el cierre permanente). Los datos del American Bankruptcy Institute muestran que 722 empresas estadounidenses solicitaron protección por quiebra en virtud del capítulo 11 en mayo, lo que supone un aumento interanual del 48\%. La pandemia puede producir un daño duradero a la economía si las empresas que dan quiebran siguen aumentando y la tasa de crecimiento potencial de la economía a largo plazo disminuye. Los encargados de la formulación de políticas deberán estar alerta y actuar con prontitud para de contener y mitigar esa eventualidad.

\section{Fuertes y rápidas repercusiones en los mercados financieros}

La pandemia de COVID-19 tuvo consecuencias graves e inmediatas en el sistema financiero mundial. En marzo, los mercados de acciones de los Estados Unidos registraron las mayores pérdidas desde la crisis financiera de 2008-2009, mientras que la demanda de activos de refugio seguro, como los títulos del Tesoro de los Estados Unidos, aumentó considerablemente.

\section{A. Mercados de acciones}

El mercado alcista que comenzó en marzo de 2009, cuando el índice Standard \& Poor's 500 (S\&P 500) tocó fondo tras la crisis financiera mundial, tenía poco más de 10 años a fines de 2019, lo que lo convierte en el más largo de la historia. Sin embargo, llegó a su fin a principios de 2020. El 31 de marzo, las acciones estadounidenses cerraron su peor trimestre desde la etapa más cruda de la crisis financiera, con los mercados tambaleándose por las cuantiosas pérdidas causadas por una economía paralizada por la enfermedad por coronavirus. Los precios de las acciones alcanzaron el máximo en febrero y el punto más bajo en marzo (véase el gráfico 6).

El S\&P 500 registró una pérdida del 20\% en el primer trimestre de 2020 (sobre la base de los precios de cierre diarios), en lo que es su descenso más pronunciado desde 2008, en tanto que la pérdida trimestral del índice medio Dow Jones de valores industriales fue del 23\%, el peor resultado desde 1987. El NASDAQ Compuesto terminó el trimestre con una caída del $14 \%$. 
Gráfico 6

Estados Unidos: índices del mercado de acciones, junio de 2010 a junio de 2020a

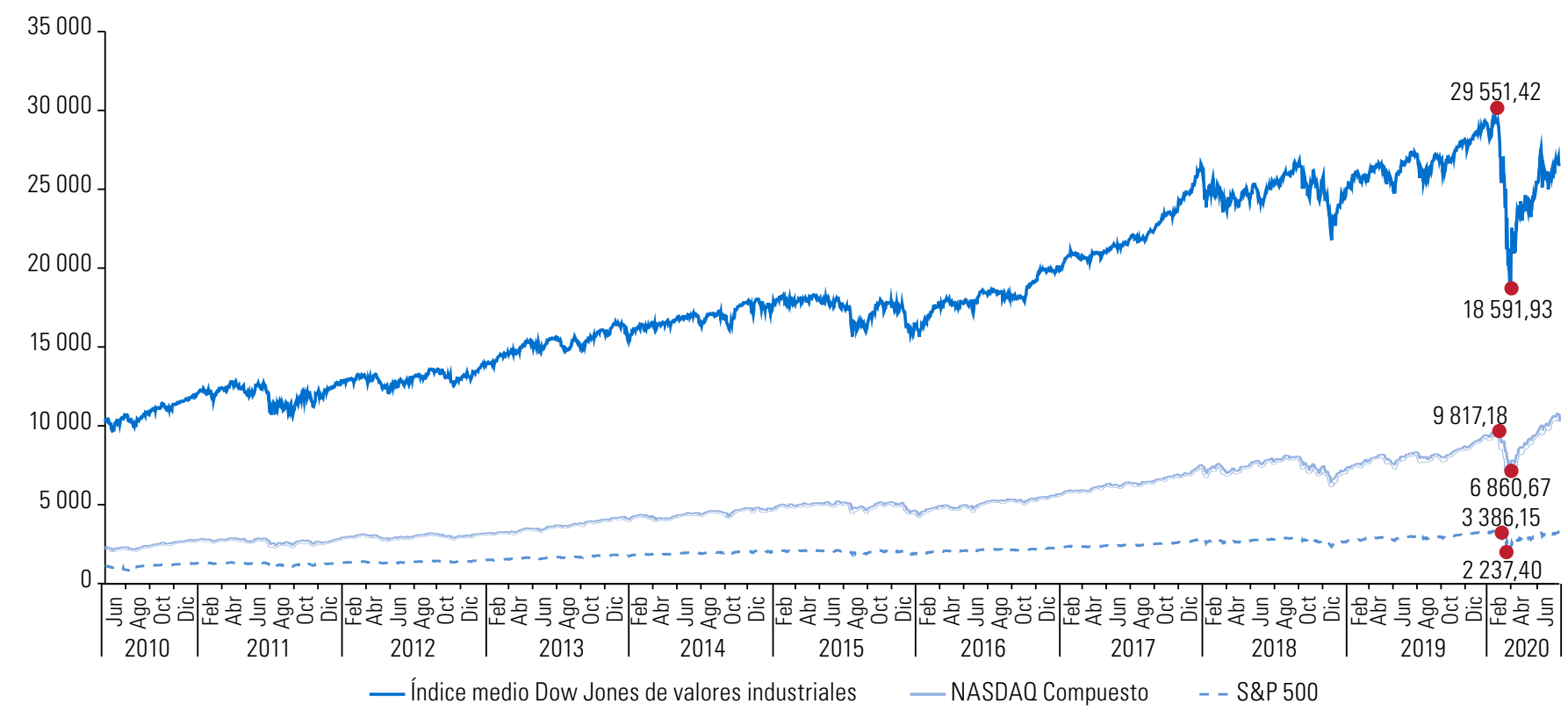

Fuente: Comisión Económica para América Latina y el Caribe (CEPAL), sobre la base de datos del Banco de la Reserva Federal de St. Louis.

${ }^{a}$ Los índices no son desestacionalizados.

Desde entonces, no obstante, las acciones se han recuperado. En el segundo trimestre, el índice medio Dow Jones de valores industriales, el S\&P 500 y el NASDAQ se recuperaron un $18 \%$, un $20 \%$ y un $31 \%$, respectivamente. Tras la publicación de las cifras positivas de empleo de mayo a principios de junio, Hertz, Whiting Petroleum, Pier 1 y JCPenney, que se habían declarado en quiebra en medio de la pandemia, vieron subir sus acciones en un repunte del mercado. Aunque las empresas que se acogen al capítulo 11 suelen sobrevivir, sus accionistas habitualmente acusan grandes pérdidas. El reciente comportamiento de los precios de las acciones ha suscitado la preocupación de que exista una desconexión de la economía real, donde la volatilidad y la incertidumbre siguen siendo elevadas.

A los mercados financieros les preocupa que un exceso de préstamos corporativos suponga un riesgo para la economía. Cuando se desató esta crisis, las empresas no financieras ya tenían una importante carga de deuda, y usaron los préstamos no para invertir, sino para comprar acciones y pagar dividendos a los accionistas. El endeudamiento excesivo podría dificultar la recuperación de la economía. También resulta preocupante el impacto de la volatilidad de los mercados bursátiles en los fondos de pensiones y en los ingresos por jubilaciones.

\section{B. Mercados de bonos}

La demanda de activos de refugio seguro, incluidos los títulos del Tesoro de los Estados Unidos, aumentó notoriamente en la medida en que se dispararon la volatilidad y la incertidumbre. Como consecuencia de ello, en el primer trimestre de 2020 se desplomaron los rendimientos de los títulos del Tesoro. La disminución de sus rendimientos a corto plazo fue más marcada que los descensos en los vencimientos a más largo plazo. En el primer trimestre, los rendimientos de los títulos del Tesoro a 3, 10 y 30 años cayeron un $82 \%$, un $64 \%$ y un $44 \%$, respectivamente. A fines de junio, los rendimientos a 3,10 y 30 años eran un $87 \%$, un $59 \%$ y un $33 \%$ más bajos, respectivamente, que a mediados de febrero, antes de que sobreviniera la pandemia (véase el gráfico 7). La disminución de los rendimientos del Tesoro es una señal de que las dudas económicas y los estímulos monetarios agresivos continúan siendo fuerzas poderosas que mantienen bajas las tasas de interés a largo plazo. 
Gráfico 7

Estados Unidos: rendimientos diarios de vencimientos constantes del Tesoro, junio de 2015 a junio de 2020

(En porcentajes)

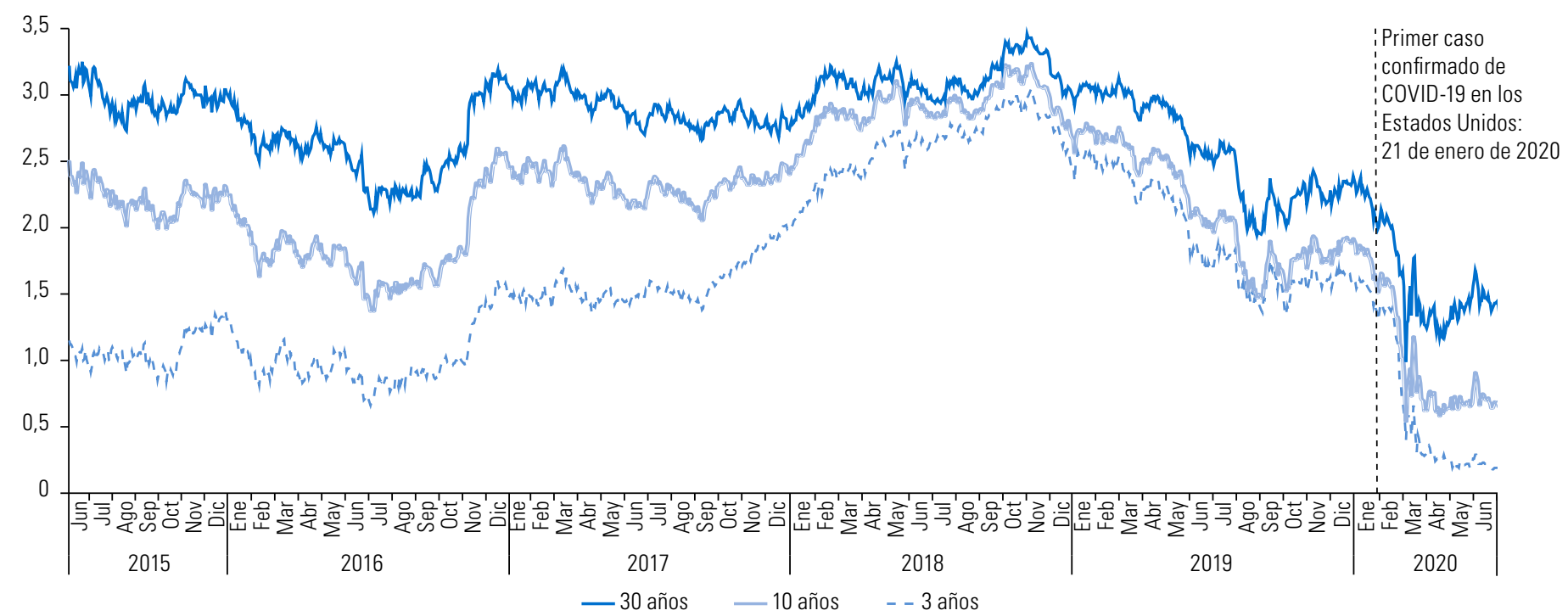

Fuente: Comisión Económica para América Latina y el Caribe (CEPAL), sobre la base de datos del Banco de la Reserva Federal de St. Louis.

\section{Condiciones financieras en América Latina y el Caribe}

En medio del colapso de los mercados financieros que tuvo lugar en la primera fase de la crisis del COVID-19 se registró una salida masiva de capitales de cartera de las economías emergentes. El Fondo Monetario Internacional (FMI) estimó esta fuga de capitales en más de 100.000 millones de dólares, cifra superior a la de la fuga de capitales ocurrida después del colapso del banco de inversiones Lehman Brothers en 2008, que desencadenó la crisis financiera internacional.

El impacto inmediato de la pandemia en las condiciones económicas de América Latina y el Caribe fue muy perjudicial, ya que se produjo una fuga ante el riesgo en medio de una crisis económica mundial que se vio agravada por un marcado descenso en los precios de los productos básicos, las remesas y los ingresos del turismo, así como del comercio mundial. La situación financiera empeoró aún más ante la fortaleza del dólar.

Con la muy intensa intervención de la Reserva Federal y de otros bancos centrales, no obstante, fue posible estabilizar los mercados financieros desde fines de marzo e incluso se logró la recuperación de las bolsas de valores del mundo 5 . Este proceso de estabilización también se tradujo en una mejora del financiamiento privado a las economías emergentes.

\section{Emisión de deuda}

Respaldados por las favorables condiciones del mercado (una combinación de amplia liquidez, bajas tasas de interés globales y una mayor tolerancia al riesgo), a comienzos de 2020, los prestatarios soberanos y corporativos de América Latina y el Caribe colocaron bonos por una cifra récord de 38.000 millones de dólares (lo que supera el máximo registrado en enero de 2018). Posteriormente, la propagación del coronavirus cambió radicalmente el panorama: se desplomaron los precios de los productos básicos (que constituyen una importante fuente de ingresos para muchos países de la región) y en febrero y marzo se detuvo la emisión de nuevas deudas transfronterizas (véase el gráfico 8).

Tras esta pausa de dos meses después de iniciada la crisis del COVID-19, las emisiones soberanas sin precedentes en abril condujeron a un repunte en la región, en la medida en que los crecientes déficits de financiamiento provocados por la pandemia y la repentina caída de los precios del petróleo hicieron aumentar el volumen de emisión ${ }^{6}$. En el segundo trimestre, las nuevas emisiones compensaron con creces el descenso anterior. La emisión total en el segundo trimestre de 2020 fue un 31\% mayor que en el mismo período de 2019.

\footnotetext{
Véase la respuesta de la Reserva Federal en la sección VI de este informe.

El 26 de marzo, Panamá emitió bonos soberanos en mercados internacionales para obtener recursos adicionales para combatir la pandemia de COVID-19. En abril le siguieron otros cuatro países de la región (Guatemala, México, Paraguay y Perú), que recurrieron a los mercados internacionales de deuda con importantes emisiones para financiar la crisis provocada por la pandemia. La demanda de estos bonos fue grande. En conjunto, estas cinco emisiones soberanas representaron 13.000 millones de dólares en nuevos bonos transfronterizos.
} 
Gráfico 8

América Latina y el Caribe: emisión de deuda mensual, junio de 2017 a junio de 2020

(En miles de millones de dólares)

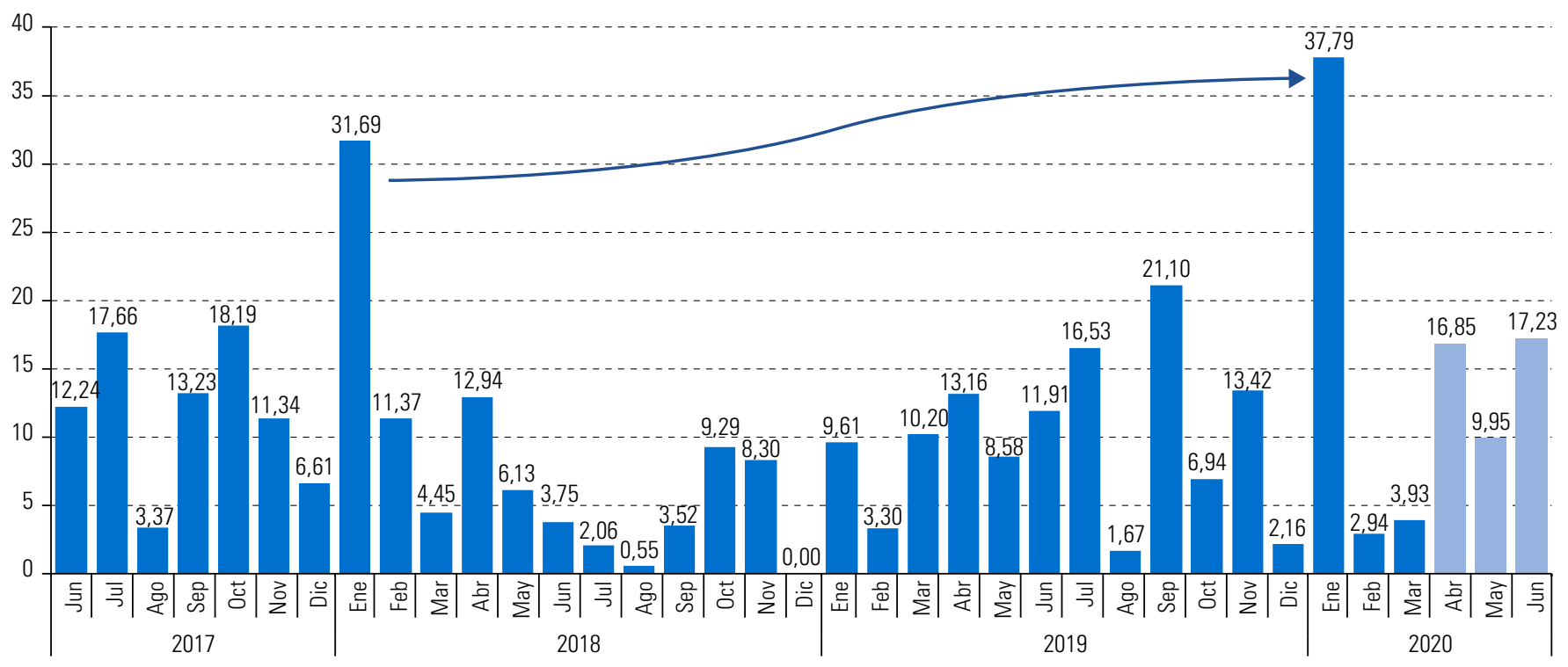

Fuente: Comisión Económica para América Latina y el Caribe (CEPAL), sobre la base de datos de Dealogic y LatinFinance.

\section{Diferenciales de la deuda}

Los diferenciales de la deuda de América Latina y el Caribe aumentaron 357 puntos básicos en el primer trimestre, y la mayor brecha se registró en marzo (275 puntos básicos). A fines de marzo, los diferenciales de la región se situaban en 703 puntos básicos, muy cerca del máximo alcanzado en noviembre de 2008, durante la crisis financiera mundial. Desde entonces, sin embargo, los diferenciales de la deuda han mostrado una tendencia a la baja (véase el gráfico 9).

Gráfico 9

Indicador de Bonos de Mercados Emergentes Global (EMBIG) y América Latina: diferenciales diarios, 2008-2020

(En puntos básicos)

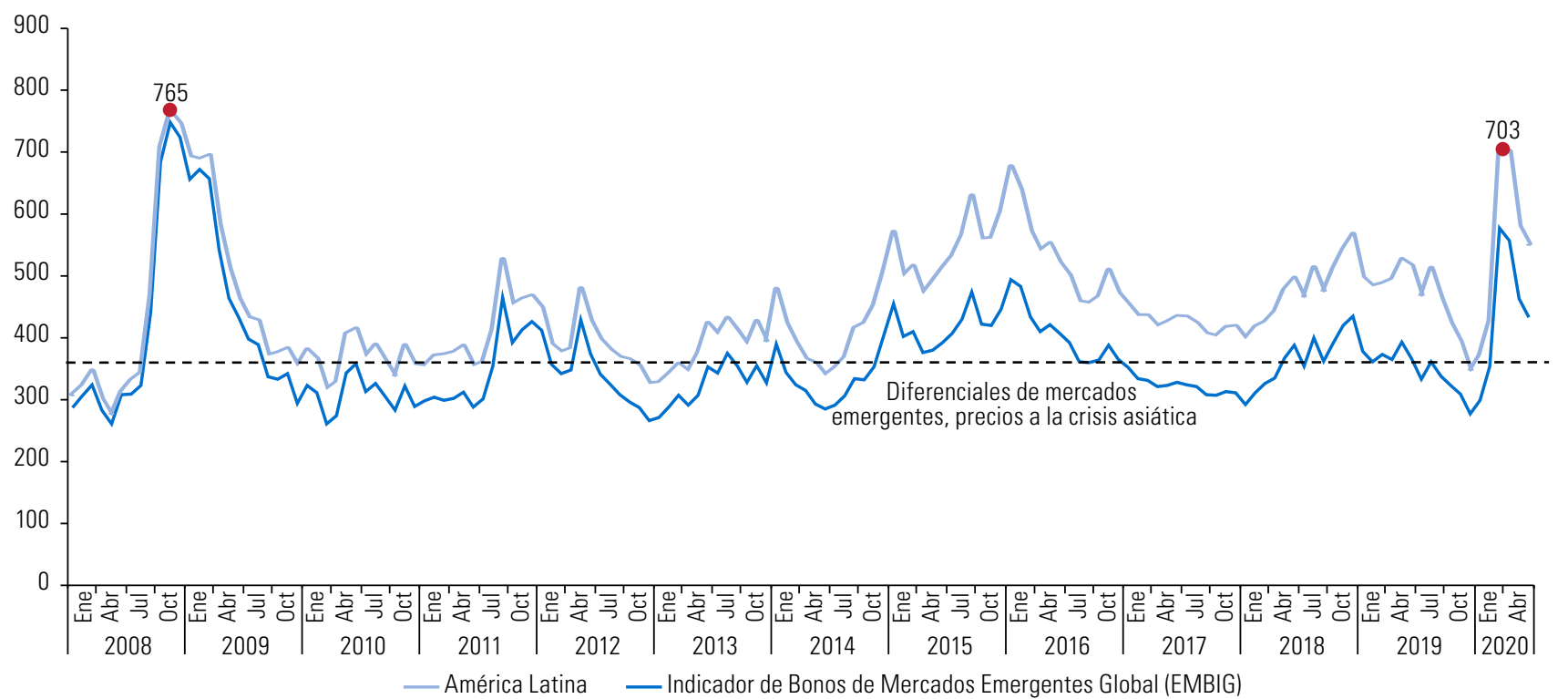

Fuente: Comisión Económica para América Latina y el Caribe (CEPAL), sobre la base de datos de JPMorgan, Emerging Markets Bond Index Monitor. 


\section{Precios de las acciones}

La pandemia también tuvo un efecto inmediato en las monedas y las acciones de América Latina: la mayoría de las monedas se depreciaron y las acciones se vendieron. El índice de precios de mercados accionarios MSCI para América Latina bajó un 46\% en el primer trimestre, mientras que los índices para los mercados emergentes y los países del Grupo de los Siete (G7) bajaron un $24 \%$ y un $21 \%$, respectivamente. Las acciones latinoamericanas alcanzaron el nivel más bajo el 23 de marzo, cuando los precios cayeron un 53\% (véase el gráfico 10).

\section{Gráfico 10}

Índices de precios del mercado bursátil, 1 de enero al 30 de junio de 2020

(Índice MSCI, 1 de enero de 2020=100)

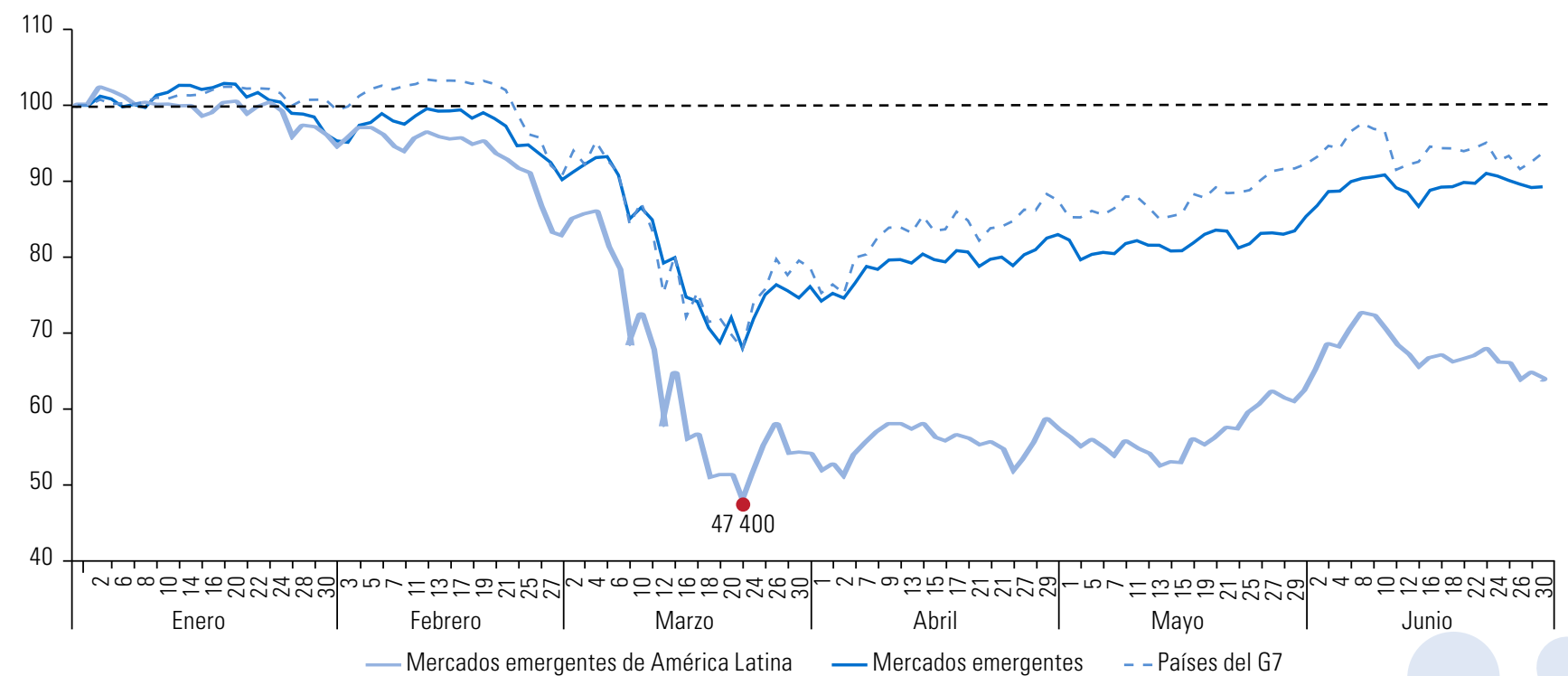

Fuente: Comisión Económica para América Latina y el Caribe (CEPAL), sobre la base de MSCI, "Index solutions" [en línea] http://www.msci.com/ products/indexes/performance.html.

Nota: El índice se basa en los precios al final de mes.

El bajo rendimiento de las acciones de América Latina se debió en parte a la depreciación de la moneda y en parte a los efectos de la pandemia y el choque petrolero en la región. Sin embargo, el aumento en los diferenciales de bonos soberanos ya mencionado y la depreciación de las monedas de América Latina y el Caribe fueron menos pronunciados que durante la crisis financiera mundial.

Desde que se alcanzó el nivel más bajo en marzo, los precios de las acciones registraron una recuperación parcial que atenuó las pérdidas totales. En el primer semestre, el índice MSCI de América Latina bajó un 36\%, al tiempo que las acciones de los mercados emergentes bajaron un $11 \%$ y las de los países del $\mathrm{G} 7$ un $6 \%$

\section{Calidad del crédito}

La calidad del crédito en la región sufrió un marcado deterioro desde comienzos de 2020 Las acciones de calificación crediticia negativas (incluidas las rebajas de la calificación y las revisiones de las perspectivas a la baja) han superado a las acciones positivas en la región durante siete años consecutivos, y la negatividad ha ido aumentando con el transcurso del año. En conjunto, desde comienzos del año ha habido 27 más rebajas que mejoras (véase el gráfico 11). También han aumentado las perspectivas negativas, lo que hace pensar que podrían registrarse más rebajas.

Solo en el mes de abril, hubo 22 acciones negativas, 14 de ellas rebajas, debido al impacto del COVID-19. Los exportadores de productos básicos de la región, en particular los países exportadores de petróleo, fueron los más afectados por las rebajas, ya que también se vieron afectados por la crisis de los precios del petróleo, el aumento de la volatilidad y el endurecimiento de las condiciones financieras 
Gráfico 11

América Latina y el Caribe: acciones de calificación crediticia neta, sobre la base de mejoras y rebajas, primer trimestre de 2015 a segundo trimestre de 2020

(En número de acciones)

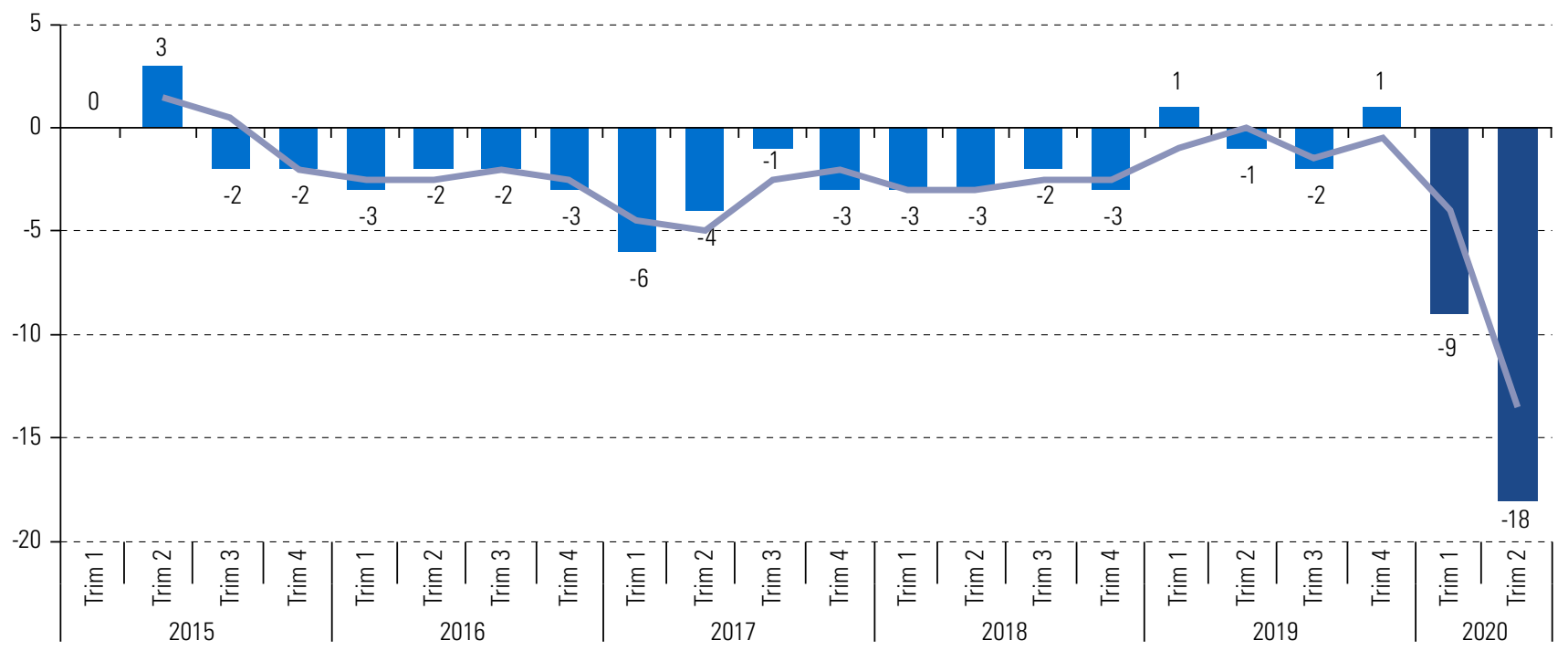

Fuente: Comisión Económica para América Latina y el Caribe (CEPAL), sobre la base de datos de Moody’s, Standard \& Poor's y Fitch.

Las rebajas han reavivado viejas críticas respecto de que las agencias de calificación crediticia tienden a agravar las condiciones financieras cuando hay una necesidad urgente de financiamiento para combatir los efectos corrosivos de una crisis. La rebaja de la calidad del crédito en un entorno de condiciones financieras estrictas y de aversión al riesgo es motivo de preocupación para los emisores

\section{Disrupción de los flujos comerciales y las cadenas de suministro}

La pandemia mundial ha afectado marcadamente a varias industrias en todo el mundo, ya que se cerraron sectores enteros de las economías, lo que condujo a la disrupción en el suministro de bienes y servicios. Los despidos masivos y la pérdida de ingresos también han debilitado mucho la demanda mundial. Las medidas de restricción de la circulación y distanciamiento físico han incidido de manera directa en el transporte, los viajes y el turismo, tres industrias directamente vinculadas al comercio de servicios. Los efectos en los flujos comerciales se ven aún más agravados por las restricciones impuestas al comercio de materiales y equipos médicos y productos farmacéuticos, y, posiblemente, de productos alimenticios

En los Estados Unidos, las exportaciones de bienes y servicios disminuyeron 141.500 millones de dólares (13,6\%) y las importaciones se redujeron 173.100 millones de dólares (13,3\%) en los primeros cinco meses de 2020 en comparación con el mismo período de 2019 Como resultado, el déficit comercial disminuyó 32.000 millones de dólares (12,2\%). Las industrias en las que más se contrajeron las exportaciones fueron: vehículos automotores, repuestos y motores (descenso de 22.800 millones de dólares o un 33\%); bienes de consumo (19.200 millones de dólares o un 21,9\%); bienes de capital (37.000 millones de dólares o un 15,9\%); servicios de viajes (33.300 millones de dólares o un 41\%), y servicios de transporte (12.800 millones de dólares o un 33\%). En el mismo período, en tanto, las mayores caídas en las importaciones también se registraron en los sectores de vehículos automotores, repuestos y motores (descenso de 49.100 millones de dólares o un 30,9\%); bienes como teléfonos móviles y otros enseres domésticos (36.300 millones de dólares o un 13,2\%); bienes de capital (28.000 millones de dólares o un 9,8\%); servicios de viajes 
(29.100 millones de dólares o un 52,3\%), y servicios de transporte (15.200 millones de dólares o un $33,6 \%)^{7}$. El descenso en el comercio de servicios se vincula directamente con las medidas de confinamiento adoptadas para controlar la propagación del COVID-19.

La caída más marcada en el comercio de los Estados Unidos en 2020 se registró en abril (véase el gráfico 12), cuando se exhortó a los ciudadanos a quedarse en casa y se aplicaron otras medidas para desacelerar la propagación del COVID-19. El cierre de la economía de los Estados Unidos comenzó a mediados de marzo y continuó por lo menos hasta mediados de mayo, cuando algunos estados comenzaron a reabrir lentamente sus economías.

Gráfico 12

Estados Unidos: comercio mensual de bienes y servicios, 2020

(En miles de millones de dólares)

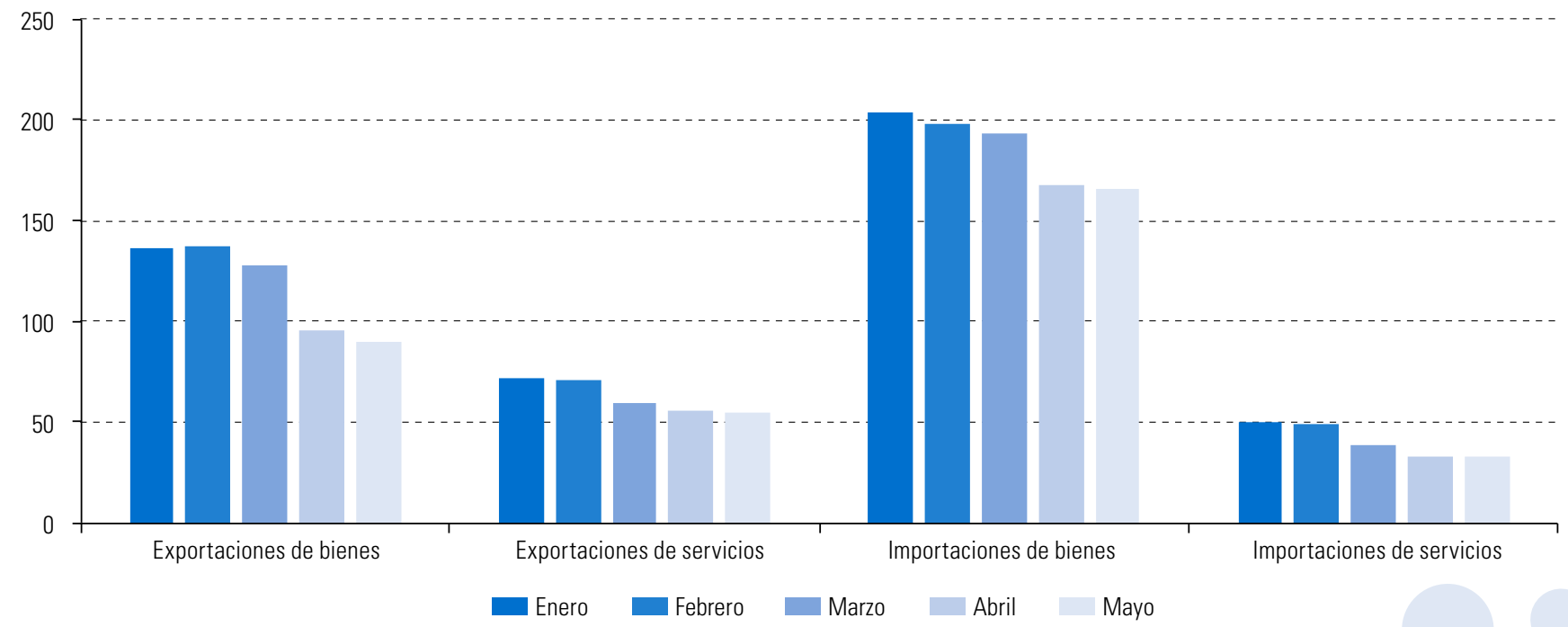

Fuente: Comisión Económica para América Latina y el Caribe (CEPAL), sobre la base de datos de la Oficina de Estadísticas Económicas y la Oficina del Censo de los Estados Unidos.

\section{A. El comercio con América Latina y el Caribe}

La disminución de la actividad económica en los Estados Unidos tiene efectos directos en la región. Uno de los principales canales de transmisión es a través de los flujos comerciales. En los primeros cinco meses del año, el comercio total de los Estados Unidos con América Latina y el Caribe se contrajo un 26\% al bajar de 369.400 millones de dólares en 2019 a 292.800 millones de dólares en 2020. Las exportaciones de bienes y servicios cayeron 35.800 millones de dólares, mientras que las importaciones anotaron un descenso de 40.000 millones de dólares. Esto dio lugar a una mejora de la balanza comercial con la región.

América del Sur fue la subregión que sufrió la mayor disminución porcentual del comercio con los Estados Unidos, con una rebaja del 20,4\%. Esto se explica sobre todo por una caída del 82\% en el comercio con la República Bolivariana de Venezuela, del 46\% con el Paraguay y del $31 \%$ con la Argentina. El comercio de los Estados Unidos con el Caribe se contrajo un $14,5 \%$ en los primeros cinco meses del año, en tanto que en los casos de Centroamérica y México las disminuciones fueron del $12,5 \%$ y el $22 \%$, respectivamente.

Las exportaciones estadounidenses de vehículos y repuestos en abril representaron aproximadamente un tercio del valor de marzo: 12.600 millones de dólares en marzo en comparación con 4.064 millones de dólares en abril. Las importaciones se redujeron más de la mitad al pasar de 30.067 millones de dólares a 13.517 millones de dólares en abril. Entre los socios comerciales más afectados en esta industria se encuentran el Canadá y México porque la industria automotriz está muy integrada a través de la cadena de valor de América del Norte.

Cifras basadas en datos oficiales. 
Debido a la naturaleza de las medidas de contención (cierre de fronteras, prohibición de viajar y medidas de cuarentena), el sector turístico enfrenta retos sin precedentes. Muchos de los países más afectados por la crisis sanitaria también desempeñan un papel crucial en el sector del turismo, como destino y fuente de turistas. Según la Organización Mundial del Turismo (OMT), representan entre el 55\% y el 88\% de los gastos mundiales de turismo. El sector turístico es vital para varios países del Caribe. Por lo tanto, esta situación se vuelve especialmente difícil para países como Antigua y Barbuda, las Bahamas, Belice, Saint Kitts y Nevis, Santa Lucía y San Vicente y las Granadinas, donde el ingreso de turistas representa más de la cuarta parte del PIB total (OMT, 2020).

\section{B. Cadenas de valor de suministro}

La pandemia de COVID-19 también ha puesto de manifiesto la dependencia de los Estados Unidos de equipo médico crítico, equipos de protección personal (EPP) y productos farmacéuticos procedentes del extranjero, así como la necesidad de coordinar medidas de emergencia sanitaria con sus vecinos más cercanos para evitar la disrupción de sus economías, que se encuentran muy integradas. También puso el foco en la necesidad de que las cadenas de suministro de alimentos sean más resilientes para garantizar la seguridad alimentaria en el país. En consecuencia, el Representante de los Estados Unidos para Asuntos Comerciales ha pedido que se adopte una política industrial pospandemia que podría incluir el aumento de los aranceles y las subvenciones para traer nuevamente al país ciertas cadenas de suministro (The Economic Club of New York, 2020).

Las cadenas de suministro han sufrido alteraciones en toda la economía. En especial, las cadenas de suministro de productos y equipos médicos, automóviles y alimentos mostraron graves disrupciones, como se indica a continuación.

\section{La cadena de valor de los suministros médicos}

La crisis sanitaria que se desató en China a principios de 2020 redujo las exportaciones de ese país y, entre otros efectos, provocó una escasez de suministros médicos esenciales en todo el mundo y especialmente en los Estados Unidos. China es uno de los principales proveedores mundiales de equipos de protección personal, dispositivos médicos, antibióticos y principios activos para la elaboración de medicamentos (Sutter, Sutherland y Schwarzenberg, 2020).

La escasez se vio agravada por el aumento de la demanda de estos productos a medida que la pandemia de COVID-19 se extendía por todo el mundo, y varios países impusieron restricciones a las exportaciones de productos médicos críticos. En los Estados Unidos, varios analistas y grupos industriales también han puesto énfasis en el papel de los aranceles en la disminución de las importaciones estadounidenses de productos médicos y sanitarios procedentes de China, lo que contribuye a la escasez de equipos médicos. Los aranceles sobre estos productos se habían elevado a partir de septiembre de 2019 en medio de las tensiones comerciales entre los Estados Unidos y China.

La respuesta comercial de los Estados Unidos a la crisis del COVID-19 se ha centrado en reducir su dependencia de la producción extranjera de suministros médicos mediante la diversificación de las cadenas de suministro y en adoptar medidas para fomentar la producción nacional de suministros y equipos médicos esenciales. Los Estados Unidos también se unieron a otros países para restringir las exportaciones de suministros médicos a partir del 10 de abril de 2020.

a) El 17 de marzo, el Representante de los Estados Unidos para Asuntos Comerciales aprobó la exclusión de las mascarillas médicas y los respiradores desechables de la lista de productos importados de China sujetos a derechos ad valorem en el marco de la controversia comercial entre los Estados Unidos y China. Los aranceles de los Estados Unidos penalizaban las importaciones de mascarillas médicas y respiradores desechables de uno de los mayores proveedores del mundo.

b) El presidente Trump invocó formalmente la Ley de Producción de Defensa para llenar los vacíos en materia de suministros médicos para combatir la pandemia de COVID-19. 
El 2 de abril, los Estados Unidos aplicaron la Ley de Producción de Defensa para exigir a la empresa 3M que priorizara los pedidos de respiradores N95 de la Agencia Federal para el Manejo de Emergencias. Al mismo tiempo, el presidente Trump pidió a 3M que aumentara la cantidad de respiradores importados hacia los Estados Unidos desde sus operaciones en el extranjero, incluida China. La Administración también pidió que 3M dejara de exportar respiradores fabricados en los Estados Unidos al Canadá y a países de América Latina; en 2019, el 34\% de los respiradores N95 producidos por 3M en los Estados Unidos se exportó al Canadá y el 30\% se exportó a México. Más adelante se dio marcha atrás con esta petición. Varias de las principales empresas dedicadas a la fabricación de automóviles, como General Motors, Ford, Fiat Chrysler Automobiles y Tesla, también han cambiado la producción de autos por la de máscaras, ventiladores y protectores faciales.

c) El 7 de abril, la Agencia Federal para el Manejo de Emergencias emitió la norma provisional "Priorización y asignación de ciertos recursos sanitarios y médicos escasos o amenazados para uso interno", publicada en el Registro Federal de Notificaciones del 10 de abril de 2020 (véase la sección 328.102(a) del nuevo Título 44 del Código de Regulaciones Federales). En esta norma provisional se establece que determinados equipos médicos necesarios para combatir el COVID-19 no se pueden exportar desde los Estados Unidos sin la aprobación explícita de la Agencia. Los materiales incluidos en esta norma son: mascarillas con filtro (por ejemplo, las designadas como N95, N99, N100, R95, R99, R100, o P95, P99, P100); respiradores purificadores de aire elastoméricos y cartuchos/filtros de partículas apropiados; mascarillas médicas de equipos de protección personal, y guantes de equipos de protección personal o guantes quirúrgicos. Esta nueva restricción a las exportaciones de los Estados Unidos implica que la Agencia Federal para el Manejo de Emergencias puede limitar lo que empresas como 3M pueden vender a los hospitales del Canadá y México.

d) El 14 de abril, el Banco de Exportación e Importación de los Estados Unidos (EXIM) anunció nuevas restricciones provisorias — hasta el 30 de septiembre de 2020 - para el financiamiento de las exportaciones estadounidenses de suministros médicos escasos, incluidos respiradores, mascarillas, guantes, trajes de Tyvek, protectores faciales y otras prendas de protección similares, necesarias para luchar contra la pandemia de COVID-19. Según las autoridades del Banco, el financiamiento de las exportaciones de equipos médicos representa un pequeño porcentaje (menos del 1\%) de la cartera de financiamiento global.

e) La Ley de Asistencia, Alivio y Protección Económica contra el Coronavirus (Ley núm. 16-136) incluye varias disposiciones orientadas a entender mejor las dependencias en la cadena de suministros médicos de los Estados Unidos (Sutter, Sutherland y Schwarzenberg, 2020), entre ellas:

i) ampliar los requisitos de notificación de escasez de fármacos;

ii) exigir a ciertos fabricantes de medicamentos que elaboren planes de gestión de riesgos;

iii) pedir a la Administración de Alimentos y Medicamentos de los Estados Unidos (FDA) que ponga a disposición del público una lista de los dispositivos médicos que se determine que están faltando, y

iv) ordenar a las Academias Nacionales de Ciencias, Ingeniería y Medicina que lleven a cabo un estudio sobre la seguridad de la cadena de suministro de productos farmacéuticos.

Muchos países de América Latina dependen de las exportaciones de suministros médicos de los Estados Unidos de al menos uno de los productos incluidos en las restricciones a las exportaciones en virtud de la nueva norma provisional (Bown, 2020; CEPAL, 2020).

Al mismo tiempo, los Estados Unidos dependen de las cadenas de suministro mundiales (y hemisféricas). En muchos casos, las instalaciones de producción de equipos de protección personal seguros y de alta calidad se encuentran en Centroamérica, el Caribe y México. En la medida en que los Estados Unidos analizan la atención de la salud con la mirada puesta en la seguridad nacional y reevalúan los costos y beneficios de la diversificación de las fuentes de suministro, podrían surgir nuevas oportunidades para que los países de América Latina y el Caribe exporten al mercado estadounidense. 


\section{La industria automotriz norteamericana}

Las cadenas mundial y norteamericana de suministro del sector automotor se han visto gravemente afectadas por la pandemia. China es uno de los principales proveedores de piezas para fábricas de automóviles en todo el mundo, y en 2018 exportó piezas por 34.800 millones de dólares (Naciones Unidas, 2020; Richter, 2020). Según la Administración de Comercio Internacional de los Estados Unidos, ese mismo año se exportaron a los Estados Unidos 11.700 millones de dólares en piezas de fabricación china (Naciones Unidas, 2020; Richter, 2020). Si bien algunas de esas piezas van a las tiendas de venta minorista de autopartes, un gran porcentaje va a las líneas de montaje y se utiliza para construir automóviles. Por lo tanto, son un elemento esencial en la cadena de suministro de América del Norte. Se estima que la propagación del coronavirus tendrá un impacto negativo de entre el $16 \%$ y el $45 \%$ en la producción de las empresas automotrices norteamericanas.

La Asociación Mexicana de Distribuidores de Automóviles (AMDA) prevé que las ventas de todos los vehículos nuevos fabricados en el país disminuyan al menos un 26\% en 2020, a unos 982.000 autos y camiones livianos (más de 330.000 unidades menos que el año anterior). Estas cifras son similares a las registradas durante la crisis financiera de 2008-2009 (Automotive News, 2020). La Asociación Mexicana de la Industria Automotriz (AMIA) estima que la industria representa alrededor del 3,8\% del PIB del país y genera unos 980.000 empleos directos (Reuters, 2020).

Desde que el Tratado de Libre Comercio de América del Norte (TLCAN), precursor del Tratado entre los Estados Unidos Mexicanos, los Estados Unidos de América y Canadá (T-MEC), entró en vigor hace 26 años, la producción de automóviles de los tres países ha estado estrechamente ligada a través de las cadenas de suministro. Cuando se produjo la crisis del COVID-19, las medidas adoptadas en distintos momentos por los Gobiernos de los tres países para contener la propagación de la pandemia y proteger la salud de los trabajadores detuvieron la producción en varias actividades, incluidas las operaciones en el sector automotor. Con la disrupción de cadenas de suministro tan estrechamente interconectadas se puso de relieve la necesidad de coordinar medidas de emergencia sanitaria entre los tres Gobiernos.

Al mismo tiempo, legisladores demócratas y republicanos enviaron una carta al Representante de los Estados Unidos para Asuntos Comerciales en la que solicitaban que se diera más tiempo al sector automotor para adaptarse a las nuevas normas de origen para el sector incluidas en el T-MEC, que entraban en vigor el $1^{\circ}$ de julio. Su argumento era que el sector automotor necesita más tiempo, en parte porque el COVID-19 ha causado el cierre temporal de algunas instalaciones de producción, mientras que otras han pasado de la producción de automóviles a la producción de equipo médico.

Las normas de contenido regional del T-MEC exigirán un 75\% de contenido norteamericano para los vehículos ligeros, en comparación con el 62,5\% exigido en el marco del TLCAN, y un $40 \%$ de contenido para los automóviles procedentes de zonas que alcancen un determinado umbral salarial (zonas de "salarios altos"). Esto se hará gradualmente en un período de tres a cuatro años, pero los fabricantes de automóviles deberán certificar el cumplimiento de los requisitos iniciales cuando el acuerdo entre en vigor.

La industria automotriz de los Estados Unidos tenía la esperanza de que se pudieran hacer algunos cambios en las regulaciones uniformes, acordadas el 3 de junio por los tres países que forman parte del acuerdo, antes de que el arreglo comercial entrara en vigor. Las regulaciones uniformes describen las normas de origen para el T-MEC, incluidas las complejas normas para los automóviles. En las regulaciones se detallan los cálculos que se utilizarán para el valor de contenido regional y los registros que deben llevar los fabricantes de automóviles para demostrar su cumplimiento. Las regulaciones establecen un período de transición de seis meses, desde la fecha de implementación del $1^{\circ}$ de julio hasta fines de 2020 
En el cuadro 1 se incluye información sobre varias medidas adoptadas por los principales fabricantes de automóviles de los Estados Unidos. El 8 de abril de 2020, el Departamento de Salud y Servicios Humanos de los Estados Unidos emitió el primer contrato a General Motors, por 489 millones de dólares, para construir 30.000 ventiladores en virtud de la Ley de Producción de Defensa.

Cuadro 1

Medidas seleccionadas adoptadas por la industria automotriz

\begin{tabular}{|c|c|c|c|c|c|c|}
\hline & Situación & Fecha de cierre & $\begin{array}{l}\text { Fecha de } \\
\text { reapertura }\end{array}$ & $\begin{array}{l}\text { Reapertura para fabricar } \\
\text { otros productos }\end{array}$ & $\begin{array}{l}\text { Empleados con } \\
\text { cese de actividad }\end{array}$ & $\begin{array}{l}\text { Cantidad de } \\
\text { empleados }\end{array}$ \\
\hline General Motors & Abierta & 19 de marzo & 18 de mayo & $\begin{array}{l}\text { Ventiladores y equipos } \\
\text { de protección personal }\end{array}$ & 50000 & 86400 \\
\hline Ford Motor Company & Abierta & 19 de marzo & 18 de mayo & $\begin{array}{l}\text { Ventiladores y equipos } \\
\text { de protección personal }\end{array}$ & 50000 & 85000 \\
\hline Toyota Motor Corporation & Abierta & 23 de marzo & 11 de mayo & & 5000 & 136000 \\
\hline Fiat-Chrysler (FCA) & Abierta & 18 de marzo & 18 de mayo & $\begin{array}{l}\text { Producción de } \\
\text { protectores faciales }\end{array}$ & 50000 & 77000 \\
\hline Honda Motor Company & Abierta & 18 de marzo & 11 de mayo & & 14000 & 27000 \\
\hline Nissan Motor Company & Cerrada & 20 de marzo & Indefinida & & 10000 & 22000 \\
\hline Hyundai-Kia Auto Group & Abierta & 30 de marzo & 5 de mayo & & & 31000 \\
\hline Subaru Corporation & Abierta & 29 de marzo & 18 de mayo & & & 5300 \\
\hline Volkswagen Group & Abierta & 17 de marzo & 18 de mayo & & & 8000 \\
\hline Mazda & Abierta & 24 de marzo & 1 de junio & & & 20000 \\
\hline Tesla & Abierta & 23 de marzo & 18 de mayo & $\begin{array}{l}\text { Producción de } \\
\text { protectores faciales }\end{array}$ & & 48000 \\
\hline BMW Group & Abierta & 29 de marzo & 4 de mayo & & 11000 & 11000 \\
\hline Volvo & Abierta & 26 de marzo & 11 de mayo & & & 17000 \\
\hline
\end{tabular}

Fuente: Comisión Económica para América Latina y el Caribe (CEPAL), sobre la base de artículos de periódicos, publicaciones específicas sobre la industria y publicaciones periódicas sobre el comercio.

\section{La cadena de suministro de alimentos}

Las cadenas de suministro de alimentos también se han visto gravemente afectadas por la pandemia. Con el cierre de restaurantes, hoteles y escuelas, los agricultores estadounidenses se vieron en dificultades para encontrar nuevos compradores para sus productos, e incluso cuando los encontraron, por dificultades de logística no pudieron colocar la mayor parte de su producción. Los minoristas registraron un aumento en la demanda de productos alimenticios, ya que la mayoría de las comidas pasaron a prepararse en los hogares, pero eso no fue suficiente para absorber los productos perecederos que estaban destinados a las escuelas, restaurantes y otros negocios. Incluso los bancos de alimentos y los programas de entrega de comida a domicilio Meals on Wheels, que se han visto desbordados por la demanda, no tienen la cantidad suficiente de refrigeradores ni de voluntarios para absorber el excedente.

Además, muchas plantas de procesamiento de carne se vieron obligadas a cerrar temporalmente cuando varios trabajadores dieron positivo en la prueba de COVID-19. Esto generó una mayor presión en la oferta de alimentos, en especial de carne, al mercado interno. La industria de elaboración de alimentos es muy vulnerable a los brotes de COVID-19 porque los empleados trabajan muy cerca unos de otros. A esto se suma la insuficiente cantidad de pruebas, que hace que algunos trabajadores que pueden estar infectados no se sometan a la prueba de detección del COVID-19, lo que precipita la propagación de la enfermedad.

Los principales procesadores de carne que han tenido que cerrar plantas son: Smithfield Foods, que procesa alrededor del 5\% de la producción de carne de cerdo de los Estados Unidos; 
JBS USA, la filial norteamericana de JBS S.A., el mayor procesador de carne del mundo; Cargill, en particular la instalación de Pensilvania, que produce filetes y carne picada de res y de cerdo; y Tyson Foods, en especial la planta procesadora de carne de cerdo en Iowa.

En este contexto, el Departamento de Agricultura (2020) anunció el Programa de Asistencia Alimentaria Coronavirus, que incluye dos elementos centrales:

a) Asistencia directa a productores agrícolas y ganaderos - El programa entregará 16.000 millones de dólares en forma de asistencia directa sobre la base de las pérdidas reales de los productores agrícolas en los casos en que los precios y las cadenas de suministro del mercado se hayan visto afectados, y ayudará a los productores con los gastos adicionales de ajuste y comercialización de 2020 debidos a la pérdida de demanda y el exceso de oferta de corto plazo a causa del COVID-19.

b) Compra y distribución a cargo del Departamento de Agricultura - El Departamento de Agricultura se asociará con distribuidores regionales y locales cuyos trabajadores se han visto considerablemente afectados por el cierre de una gran cantidad de restaurantes, hoteles y otras entidades de servicios alimentarios, para comprar 3.000 millones de dólares en productos frescos, lácteos y carne. Además, los distribuidores y mayoristas entregarán una caja preaprobada de productos frescos, lácteos y carne a los bancos de alimentos, organizaciones comunitarias y religiosas, y otras organizaciones sin fines de lucro que brindan servicios a los ciudadanos que lo necesitan.

Además de estos programas específicos, el Departamento de Agricultura anunció que utilizaría otras fuentes de financiamiento disponibles para comprar y distribuir alimentos entre los más necesitados.

La Administración también aprobó un decreto para aumentar la competitividad del país en la industria de los frutos de mar y proteger la cadena de suministro de este tipo de alimentos. Este decreto ordena a los organismos que amplíen la producción sostenible de frutos de mar en los Estados Unidos, lo que incluye habilitar procesos de concesión de permisos de acuicultura más eficientes y previsibles, acelerar la reforma normativa para maximizar la pesca comercial y mantener las restricciones sobre las importaciones de frutos de mar que no cumplan las normas de los Estados Unidos. El presidente Trump también anunció la disponibilidad de 300 millones de dólares para apoyar a pescadores y otros negocios afines afectados por la pandemia.

\section{Fuerte impacto en la migración}

\section{A. Flujos migratorios}

Casi todos los países del hemisferio occidental cerraron las fronteras a los migrantes o aplicaron prohibiciones de viajar, en un intento de controlar la propagación del COVID-19.

Entre las medidas adoptadas en los Estados Unidos figuran restricciones a los viajes y, en especial, la suspensión de la entrada —como inmigrantes o no inmigrantes - de aquellos ciudadanos extranjeros que en los 14 días previos hubieran estado en Alemania, Austria, Bélgica, el Brasil, Chequia, China, Dinamarca, Eslovaquia, Eslovenia, España, Estonia, Finlandia, Francia, Grecia, Hungría, Irán (República Islámica del), Irlanda, Islandia, Italia, Letonia, Liechtenstein, Lituania, Luxemburgo, Malta, Mónaco, Noruega, los Países Bajos, Polonia, Portugal, el Reino Unido, San Marino, la Santa Sede, Suecia y Suiza.

Los Estados Unidos firmaron acuerdos recíprocos con el Canadá y México para restringir los viajes no esenciales a través de sus fronteras terrestres norte y sur ${ }^{8}$. Además, los Estados Unidos anunciaron que los extranjeros que cruzaran por los puntos de entrada o que por alguna otra razón no tuvieran permitido el ingreso serán inmediatamente devueltos, ya que las instalaciones en las que normalmente quedarían retenidos no cuentan con las condiciones necesarias para cumplir con la cuarentena durante el tiempo necesario para evaluar posibles casos.

Estas medidas entraron en vigor el 21 de marzo de 2020 y en principio tendrían una vigencia de 30 días. No obstante, ya se prorrogaron tres veces y actualmente están vigentes hasta el 21 de septiembre de 2020. 
El presidente Trump ordenó una serie de restricciones sin precedentes vinculadas a la inmigración y las fronteras. En marzo, autorizó a la Oficina de Aduanas y Protección Fronteriza a hacer uso de la potestad de su Administración en materia de salud pública de emergencia, en virtud del Título 42 del Código de los Estados Unidos, una disposición que data de los años cuarenta, de eludir los procedimientos normales de inmigración y expulsar de inmediato a los migrantes. En abril, el Gobierno anunció un conjunto de políticas que suponen requisitos más estrictos para obtener el permiso de residencia. El 11 de junio, el Departamento de Educación emitió una norma de emergencia que prohíbe a las universidades conceder fondos de asistencia para el coronavirus a estudiantes extranjeros e indocumentados, incluidos los protegidos por la política de Acción Diferida para los Llegados en la Infancia (DACA). La Administración también declaró que se encuentra analizando la implementación de restricciones a las nuevas visas H-1B para trabajadores calificados.

Como resultado de estas medidas, los cruces no autorizados por la frontera sur de los Estados Unidos bajaron un 50\% en abril de 2020, según las cifras publicadas por las autoridades federales. Las autoridades fronterizas detuvieron a 16.039 migrantes en abril, lo que muestra un descenso respecto de los 30.236 detenidos en marzo. En mayo la cifra aumentó y 23.197 personas fueron detenidas en la frontera sur. En junio y julio el número de personas detenidas en la frontera sur siguió aumentando a 32.935 y 40.746, respectivamente.

En abril, la Oficina de Aduanas y Protección Fronteriza llevó a cabo 14.416 expulsiones y los agentes estadounidenses detuvieron, procesaron y devolvieron migrantes a México en menos de 24 horas. En consecuencia, el número de detenidos en las estaciones fronterizas de los Estados Unidos se redujo de más de 3.000 por día a unos 100, según lo informado por la Oficina de Aduanas y Protección Fronteriza.

Además de a sus propios ciudadanos, las autoridades mexicanas acordaron recibir a los ciudadanos guatemaltecos, hondureños y salvadoreños expulsados por las autoridades estadounidenses. Según las cifras de la Oficina de Aduanas y Protección Fronteriza (2019), los ciudadanos de estos cuatro países representan aproximadamente el 95\% de los cruces ilegales.

\section{B. Poblaciones de migrantes en los Estados Unidos}

Los negocios más afectados por las medidas de confinamiento -como restaurantes, salones de belleza, hoteles y servicios de limpieza- dependen, en gran medida, de los trabajadores migrantes, que se espera que se vean afectados de manera desproporcionada por la pandemia. Muchos de ellos carecen o tienen un acceso limitado a cualquier tipo de protección social, lo que aumenta su vulnerabilidad.

En un estudio realizado recientemente por Borjas y Cassidy (2020) se da cuenta de que los inmigrantes se vieron desproporcionadamente afectados por los efectos del COVID-19 en el mercado laboral de los Estados Unidos. Sobre la base de datos de los archivos mensuales básicos de la Encuesta Continua de Población, en la investigación se muestra que, si bien históricamente los hombres inmigrantes tenían más probabilidades de estar empleados que los hombres nativos, en abril de 2020, las tasas de empleo eran más bajas entre los inmigrantes que entre los nativos. Los autores señalan que este cambio se debió tanto a que la tasa de pérdida de empleo de los hombres inmigrantes empleados aumentó en relación con la de los nativos, como a que la tasa a la cual los inmigrantes sin trabajo podían encontrar empleo disminuyó en relación con la de los nativos. Esto se explica, en parte, por el hecho de que era menos probable que los inmigrantes tuvieran trabajos que se pudieran realizar a distancia y las consecuencias laborales que sufrieron fueron dispares (Borjas y Cassidy, 2020)

La población latina en los Estados Unidos se ha visto desproporcionadamente afectada por el COVID-19, y el número de latinos infectados superó al que se hubiera esperado en virtud de su proporción en la población. La falta de acceso a servicios de atención médica supone todo un reto en este caso.

Los trabajadores migrantes también contribuyen en gran medida a la industria agroalimentaria. Según la Organización de las Naciones Unidas para la Agricultura y la 
Alimentación (FAO, 2020), los trabajadores migrantes en los Estados Unidos, contratados para ocupar puestos de trabajo temporales o de temporada en el sector agrícola, constituyen el $10 \%$ de los trabajadores agrícolas de zonas de cultivos, en tanto que el sector de los frutos de mar, sobre todo en Alaska, atrae cada año a más de 20.000 trabajadores migrantes. La escasez de mano de obra extranjera, debido al cierre de las fronteras internacionales y a las restricciones impuestas a los viajes, plantea un gran reto, que repercute en las cadenas de valor agrícolas, los precios y la disponibilidad de algunos productos.

El Departamento de Seguridad Nacional de los Estados Unidos publicó un memorando sobre la "Identificación de trabajadores esenciales de infraestructura crítica durante la respuesta al COVID-19", donde se incluye a los trabajadores de la industria de suministro de alimentos, junto con los de la industria farmacéutica y los que prestan servicios de atención sanitaria, como esenciales y que, por lo tanto, tienen la responsabilidad de seguir trabajando durante la emergencia sanitaria. Aunque declarados esenciales, gran parte de los migrantes son indocumentados y trabajan en el sector agrícola en virtud de acuerdos informales o casuales. Poco después, el Servicio de Inmigración y Control de Aduanas de los Estados Unidos emitió un comunicado en el que anunciaba que, ante la pandemia de COVID-19, ajustaría temporalmente sus procedimientos de aplicación de la ley para dejar de centrarse en los inmigrantes indocumentados comunes y centrarse en aquellos que representan una amenaza desde el punto de vista penal o de seguridad pública.

Sin embargo, los 60 millones de hispanos que viven en los Estados Unidos tienen procedencias y estilos de vida sumamente diversos — desde inmigrantes recién llegados y familias de varias generaciones, hasta profesionales con altos ingresos y trabajadores agrícolas migrantes pobres-, y los efectos de la pandemia dejan al descubierto esa gran variedad.

Los datos de algunos estados donde la población hispana se ha asentado hace mucho tiempo y es más estable, como Arizona y Texas, muestran tasas de infección similares a la proporción que representan en el total de la población. Los hispanos de Nuevo México, que constituyen la mitad de la población y tienen una presencia de larga data en el estado, tienen aproximadamente el mismo número de casos que el resto de la población.

Se espera que la pandemia incida en las remesas. Los servicios, en especial aquellos que más dependen de los trabajadores migrantes (como hoteles, restaurantes, servicios de limpieza y salones de belleza), han sido los más afectados por las restricciones a la circulación, el distanciamiento físico y los cierres temporales. La pérdida de puestos de trabajo en este sector repercutirá directamente en las remesas. Además, a aquellos migrantes que logren mantener sus ingresos puede resultarles difícil enviar remesas a su país de origen, ya que en la mayoría de los países no se reconoce la transferencia internacional de dinero como un servicio esencial, y los bancos y otros organismos pueden estar cerrados o funcionar con un horario reducido.

El Banco Mundial ha estimado que los flujos globales de remesas hacia América Latina y el Caribe disminuirán un 19,3\% en 2020 (Banco Mundial, 2020). El Diálogo Interamericano (2020) estimó que las remesas de los Estados Unidos a América Latina y el Caribe se reducirían un 7\%, de 76.000 millones de dólares en 2019 a 70.000 millones de dólares en 2020 (sin calcular los daños a los afectados directamente por el COVID-19).

\section{La respuesta de política económica de los Estados Unidos: rápida y contundente}

La velocidad con que los encargados de la formulación de políticas en los Estados Unidos adoptaron distintas medidas orientadas a mitigar el impacto económico de la pandemia en los hogares y las empresas, así como la magnitud de dichas medidas, no registran precedentes.

\section{A. Política monetaria}

Para hacer frente a los problemas económicos generados por la pandemia de COVID-19, la Reserva Federal ha adoptado medidas más rápido y de más amplio alcance que nunca (véase el gráfico 13). Basándose en la respuesta que ofreció a la crisis financiera mundial de 2008-2009, el banco central pudo relanzar un conjunto de herramientas probadas 
para enfrentar crisis y, sobre esa base, también diseñó nuevas herramientas en menos de 100 días desde que comenzó la pandemia (en comparación con los más de 500 días que esto le llevó cuando sobrevino la crisis financiera mundial).

\section{Gráfico 13}

Tasa de interés de los fondos federales de los Estados Unidos: ayer y hoy (En porcentajes)

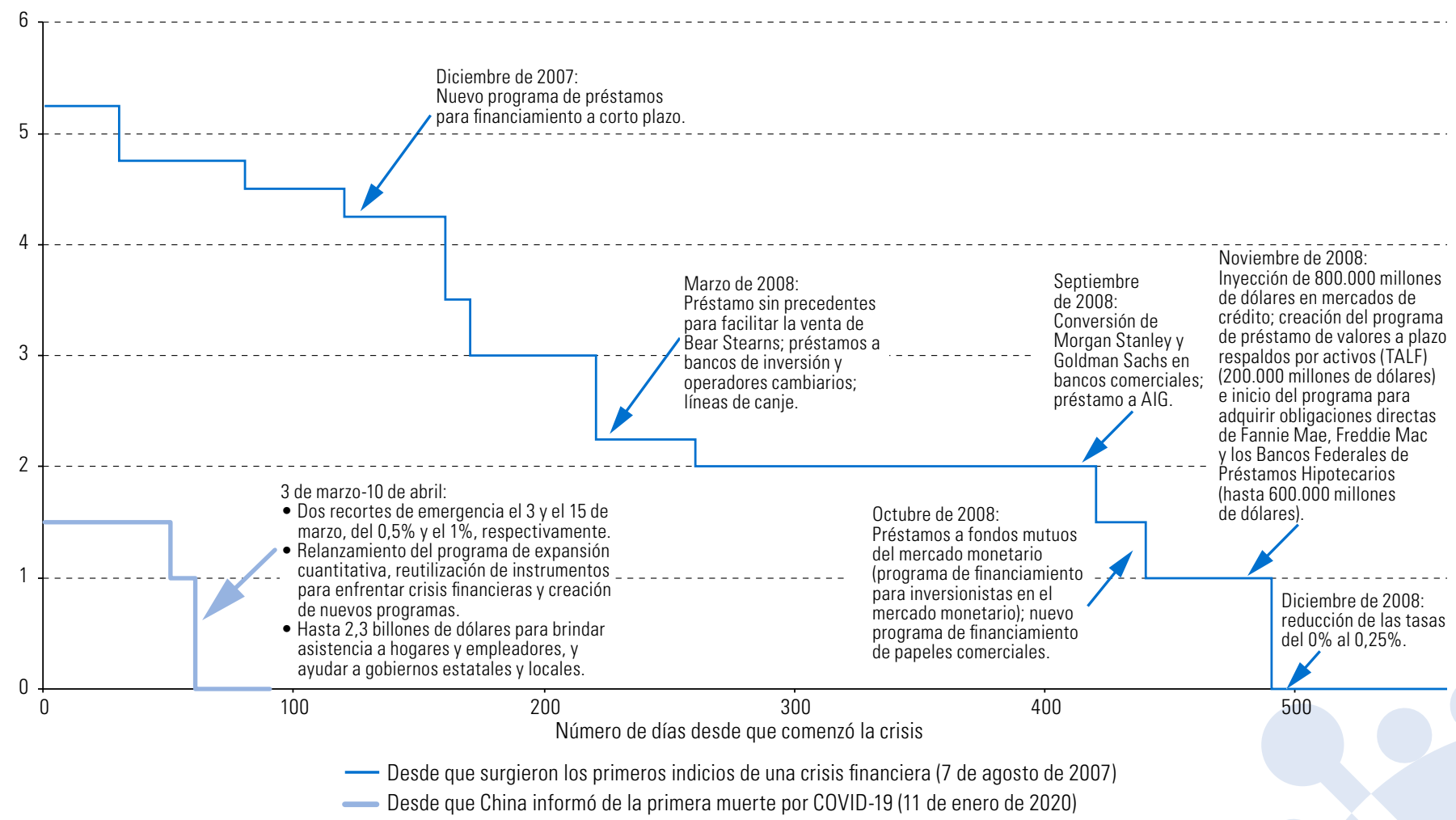

Fuente: Comisión Económica para América Latina y el Caribe (CEPAL), sobre la base de datos de la Reserva Federal de los Estados Unidos y J. M. Schlesinger y H. Sender, "How fast the economy crashed and Washington responded —in charts", Wall Street Journal, 27 de marzo de 2020 [en línea] https://www.wsj.com/articles/how-fast-the-economy-crashed-and-washington-respondedin-charts-11585334137.

Nota: Los primeros indicios de la crisis financiera mundial surgieron en agosto de 2007 , cuando los valores respaldados por hipotecas de alto riesgo se desplomaron.

La Reserva Federal redujo las tasas de interés, ofreció una expansión cuantitativa ilimitada y recurrió tanto a instrumentos nuevos como a otros ya conocidos (que se habían usado como respuesta a la crisis financiera de 2008-2009) con el propósito de mantener en funcionamiento los mercados financieros.

\section{Tasas de interés}

El Comité de Mercado Abierto de la Reserva Federal, que establece la política monetaria de los Estados Unidos, celebró dos reuniones no programadas el 3 y el 15 de marzo, en las que se decidió efectuar recortes de emergencia de las tasas de interés del 0,5\% y el 1\%, respectivamente. En consecuencia, la Reserva Federal redujo las tasas hasta el límite inferior de cero, con un intervalo objetivo de 0 a 25 puntos básicos, como en los años posteriores a la crisis financiera mundial (véase el gráfico 14). En su declaración del 15 de marzo, la Reserva Federal recurrió al preanuncio monetario (forward guidance), una herramienta de su arsenal para crisis financieras, para indicar que espera mantener este intervalo objetivo hasta que esté segura de que la economía ha resistido los últimos acontecimientos y está en vías de alcanzar sus objetivos máximos de empleo y estabilidad de precios. En las nuevas proyecciones publicadas el 10 de junio, los 17 funcionarios que participan en las reuniones de fijación de las tasas dijeron que esperaban mantener las tasas cerca de cero el próximo año, y 15 de ellos prevén que las tasas se mantendrán constantes hasta 2022. 
Gráfico 14

Tasa de interés de los fondos federales de los Estados Unidos (En porcentajes)

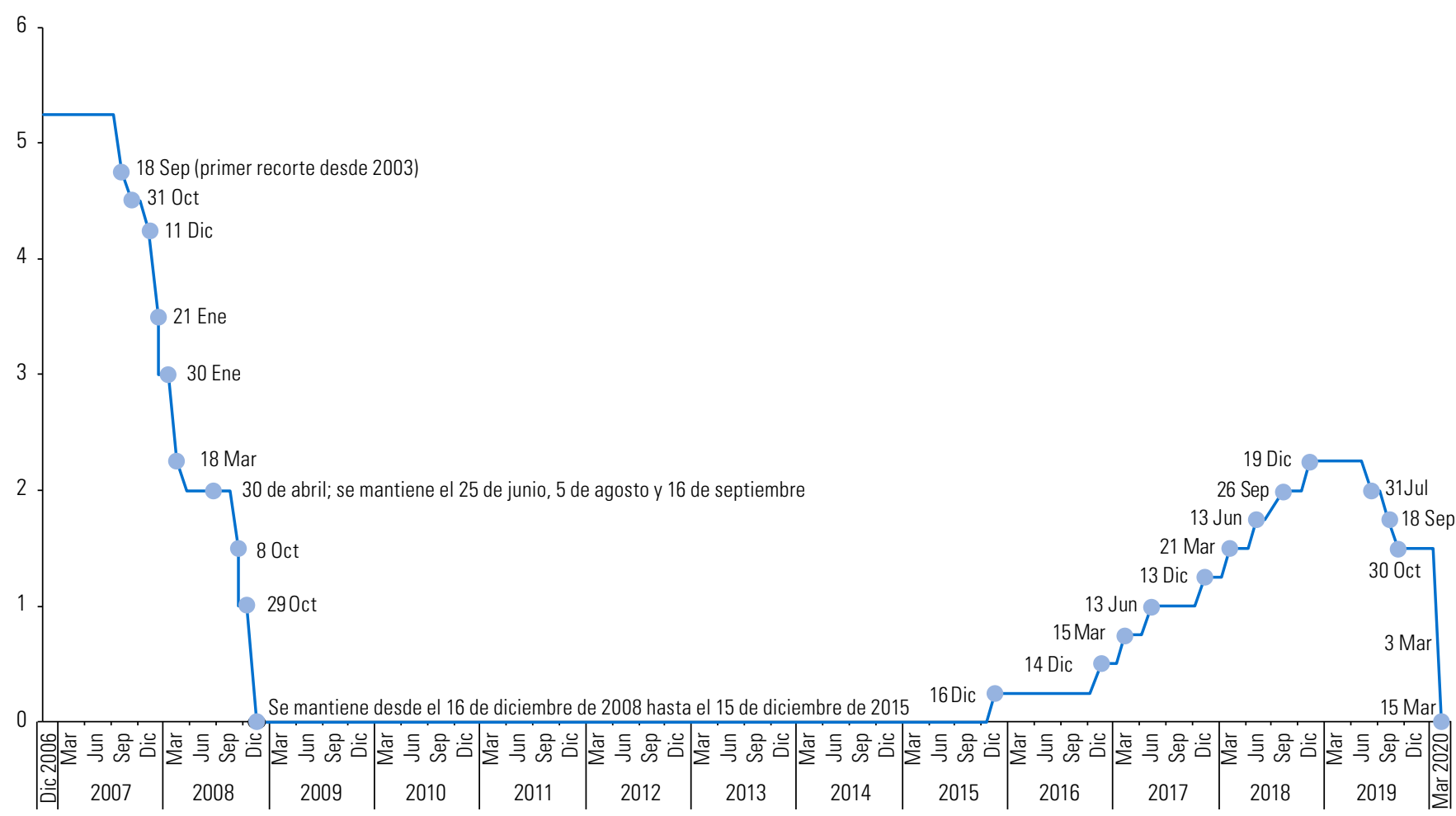

Fuente: Comisión Económica para América Latina y el Caribe (CEPAL), sobre la base de datos de la Reserva Federal de los Estados Unidos.

\section{Expansión cuantitativa}

El 15 de marzo, la Reserva Federal reanudó su programa de expansión cuantitativa y anunció que en los próximos meses aumentaría al menos 500.000 millones de dólares su cartera de títulos del Tesoro y al menos 200.000 millones de dólares su cartera de títulos con garantía hipotecaria de agencias patrocinadas por el gobierno para apoyar el buen funcionamiento de los mercados de títulos del Tesoro y de títulos con garantía hipotecaria de agencias cuasigubernamentales, que son fundamentales para el flujo de crédito hacia los hogares y las empresas. El 23 de marzo, la Reserva Federal fue más allá y se comprometió a compras ilimitadas de bonos del Tesoro de los Estados Unidos y de títulos con garantía hipotecaria de agencias cuasigubernamentales. La eliminación de topes en las compras planificadas de expansión cualitativa también hizo que el balance de la Reserva Federal aumentara notablemente de tamaño, en la medida en que se convirtió en el comprador de último recurso en los mercados de renta fija.

El balance de la Reserva Federal aumentó hasta alcanzar un máximo de 7,17 billones de dólares a principios de junio (el máximo anterior había sido de 4,5 billones de dólares a principios de 2015), a los que se sumaron 3 billones de dólares en marzo, abril y mayo. Si bien el aumento provino principalmente de la compra de bonos del Tesoro y títulos con garantía hipotecaria de agencias cuasigubernamentales (6 billones de dólares), el otro componente clave fue la expansión de 445.000 millones de dólares de las líneas de intercambio de divisas, según datos del banco central (véase el recuadro 1). Hasta el momento, la demanda de la oferta de dólares de la Reserva Federal no ha superado los niveles observados durante la crisis financiera mundial, que fue la última vez que el banco central lanzó medidas similares de impulso de la liquidez. En diciembre de 2008, en el momento más álgido de la crisis financiera, se captaron 583.000 millones de dólares a través de las líneas de intercambio de divisas. 
Recuadro 1

La respuesta de la Reserva Federal a la pandemia de COVID-19

Tasas de interés: El 15 de marzo, la Reserva Federal llevó las tasas de interés al límite inferior de cero y utilizó la herramienta de preanuncio monetario

Expansión cuantitativa: Esta medida se anunció el 15 de marzo y el 23 de marzo se amplió a compras ilimitadas de títulos del Tesoro de los Estados Unidos y de títulos con garantía hipotecaria de agencias estadounidenses.

Ventanilla de descuento: El 15 de marzo, la Reserva Federal abrió su ventanilla de descuento a los bancos comerciales y los instó a utilizar sus propias reservas de capital para ampliar los préstamos a los hogares y las empresas, ya que los sectores de servicios de la economía que implicaban un contacto personal se habían detenido cuando el distanciamiento físico se convirtió en la norma.

Tasa de crédito primaria: El 15 de marzo, la Reserva Federal anunció que reduciría la tasa de crédito primaria en 150 puntos básicos, hasta situarla en el 0,25\%. Esta fue una medida enérgica del banco central, ya que implicó que, a partir de ese momento, la tasa de descuento fuera igual a la tasa de interés a un día, con el objetivo de eliminar el estigma asociado con la utilización de la ventanilla de descuento de la Reserva Federal.

Requisitos que se imponen a los bancos: El 15 de marzo, la Reserva Federal eliminó los requisitos de reserva y con ello liberó unos 140.000 millones de dólares de capacidad para que los bancos los redistribuyeran en otras áreas, como el mercado de los acuerdos de recompra, que recientemente había adolecido de falta de capacidad. El 23 de marzo, con el propósito de alentar a las instituciones financieras a utilizar sus reservas de capital y liquidez para apoyar la economía durante la pandemia de COVID-19, la Reserva Federal modificó el régimen de la capacidad total de absorción de pérdidas que debían tener los ocho bancos estadounidenses de importancia sistémica internacional y los bancos extranjeros designados que tenían operaciones en los Estados Unidos

Líneas de canje: El 15 de marzo, la Reserva Federal, el Banco del Canadá, el Banco de Inglaterra, el Banco del Japón, el Banco Central Europeo (BCE) y el Banco Nacional de Suiza anunciaron una acción coordinada para aumentar la aportación de liquidez mediante los mecanismos permanentes de líneas de canje de liquidez en dólares. Estas líneas de canje son un mecanismo eficaz para que los bancos centrales del mundo puedan obtener dólares a cambio de su propia moneda.

El 19 de marzo, la Reserva Federal amplió las líneas de canje a otros países y dijo que cada una de las nuevas líneas —que tenían una duración mínima de seis meses - proporcionarían 60.000 millones de dólares de liquidez en dólares a los bancos centrales de Australia, el Brasil, la República de Corea, México, Singapur y Suecia, así como 30.000 millones de dólares a los bancos centrales de Dinamarca, Noruega y Nueva Zelandia.

Mercado de acuerdos de recompra: La Reserva Federal ha ampliado en gran medida el alcance de sus operaciones de recompra para inyectar efectivo en los mercados monetarios. Básicamente ofrece un suministro ilimitado de dinero. El 16 de marzo, después de que aparecieran signos de tensión a pesar de las medidas de emergencia que se habían adoptado el día anterior,

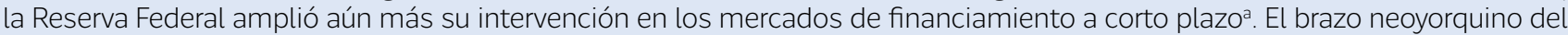
banco central dijo que estaría dispuesto a proporcionar 500.000 millones de dólares adicionales en financiamiento a un día en el mercado de los acuerdos de recompra, donde los inversores intercambian garantías de alta calidad, como pagarés del Tesoro, por dinero en efectivo.

Programa de financiamiento de papeles comerciales (Commercial Paper Funding Facility (CPFF)): El 17 de marzo, la Reserva Federal también ofreció al sector empresarial de los Estados Unidos una vía de salvación directa, al anunciar que comenzaría a comprar papeles comerciales mediante un servicio que se había utilizado por última vez durante la crisis financiera de 2008 y 2009. El 23 de marzo, la Reserva Federal anunció que en el programa de financiamiento de papeles comerciales se admitiría deuda de alta calidad emitida por los municipios. La Reserva Federal creó el nuevo servicio con arreglo al párrafo 3 del artículo 13 de la Ley de la Reserva Federal, lo que significa que actuó con la aprobación de Steven Mnuchin, Secretario del Tesoro de los Estados Unidos. El último programa de papeles comerciales que se había originado en la crisis financiera mundial se cerró en 2010

Servicio de crédito para operadores primarios (Primary Dealer Credit Facility (PDCF)): El 17 de marzo, la Reserva Federal también adoptó nuevas medidas enérgicas para reforzar la liquidez en los mercados financieros, al permitir que los operadores autorizados de deuda pública, incluidos los bancos más grandes, obtuvieran préstamos en efectivo con la garantía de algunas acciones, deuda municipal y bonos empresariales de alta calificación. Esta medida, que permitió volver a poner en práctica una herramienta que se había utilizado durante la última crisis financiera, puso de relieve la preocupación de la Reserva Federal por la solidez de los mercados de financiamiento a corto plazo, que se habían visto sumidos en el caos debido a la pandemia

El servicio de crédito para operadores primarios ofrece financiamiento a un día y a plazo con vencimientos de hasta 90 días, y se puso a disposición de los operadores el 20 de marzo de 2020. Se ofrecerá durante al menos seis meses y podría prorrogarse si fuera necesario. Como garantía del crédito otorgado a los operadores primarios de conformidad con este servicio se puede utilizar una amplia gama de títulos de deuda con grado de inversión, entre ellos, papeles comerciales y bonos municipales, y una variedad de títulos de capital. La tasa de interés que se cobrará será la tasa de crédito primaria, o la tasa de descuento, del Banco de la Reserva Federal de Nueva York. 
Programa de liquidez de fondos mutuos del mercado monetario (Money Market Mutual Fund Liquidity Facility (MMLF)): Mediante este programa, que se puso en marcha el 18 de marzo, las instituciones financieras que reúnen las condiciones necesarias pueden obtener préstamos respaldados por activos de alta calidad que hayan adquirido a fondos mutuos del mercado monetario. El 20 de marzo la Reserva Federal amplió este programa para incluir algunos fondos municipales del mercado monetario, y el 23 de marzo dijo que incluiría una gama más amplia de valores, entre ellos, los pagarés municipales a la vista de tasa variable y los certificados bancarios de depósito.

Este fue el tercer servicio que la Reserva Federal anunció en una semana, y se creó alegando facultades de excepción para conceder créditos, tras los esfuerzos anteriores por respaldar el mercado de deuda comercial a corto plazo y ampliar los préstamos destinados a las grandes instituciones financieras conocidas como operadores primarios, que desempeñan el papel de contrapartes exclusivas de la Reserva Federal en los mercados. Esos servicios requirieron la aprobación del Secretario del Tesoro, Steven Mnuchin. La Reserva Federal dijo que recibiría 10.000 millones de dólares del Tesoro para cubrir las posibles pérdidas que surgieran del Fondo de Estabilización Cambiaria (ESF)

Programa de préstamo de valores a plazo respaldados por activos (Term Asset-Backed Securities Loan Facility (TALF): El 23 de marzo, la Reserva Federal anunció el relanzamiento de otro servicio de los tiempos de la crisis financiera. En 2008, había utilizado el servicio de préstamos a plazo con garantía de valores respaldados por activos para apoyar a los mercados de crédito al consumo y a las empresas. Este servicio da a la Reserva Federal la posibilidad de comprar valores respaldados por préstamos estudiantiles y automotores, así como por préstamos de tarjetas de crédito y por los otorgados a las empresas mediante la Agencia Federal para el Desarrollo de la Pequeña Empresa.

Programa de crédito para empresas en el mercado primario (Primary Market Corporate Credit Facility (PMCCF)): El 23 de marzo, la Reserva Federal también anunció el lanzamiento de este nuevo servicio, que se creó para promover la emisión de nuevos bonos y préstamos. Mediante este mecanismo se otorgan préstamos a empresas que tienen grado de inversión y se proporciona financiamiento transitorio de cuatro años.

Programa de crédito para empresas en el mercado secundario (Secondary Market Corporate Credit Facility (SMCCF)): El 23 de marzo se anunció otro nuevo servicio, que se creó a los efectos de proporcionar liquidez para adquirir bonos empresariales en circulación. Mediante este mecanismo se compran bonos empresariales emitidos por empresas de alta calificación y fondos de inversión negociados en mercados bursátiles de los Estados Unidos, en el mercado de los bonos empresariales que tienen grado de inversión

El programa de préstamo de valores a plazo respaldados por activos (TALF), el programa de crédito para empresas en el mercado primario (PMCCF) y el programa de crédito para empresas en el mercado secundario (SMCCF) fueron diseñados para que se pudiera ofrecer nuevo financiamiento por un importe de 300.000 millones de dólares. El Departamento del Tesoro cubrirá pérdidas por 30.000 millones de dólares.

Programa de acuerdo de recompra para autoridades monetarias extranjeras e internacionales (Repurchase Agreement Facility for Foreign and International Monetary Authorities (FIMA)): El 31 de marzo, la Reserva Federal anunció la creación de este servicio que, junto con las líneas de canje de liquidez en dólares, tiene por objeto contribuir a aliviar las tensiones en los mercados mundiales de financiamiento en esa moneda. El servicio permite a los titulares de cuentas que son autoridades monetarias extranjeras e internacionales — bancos centrales y otras autoridades monetarias internacionales que tienen cuentas en el Banco de la Reserva Federal de Nueva York - concertar acuerdos de recompra con la Reserva Federal para intercambiar temporalmente títulos del Tesoro de los Estados Unidos por dólares. Estará disponible durante seis meses.

Flexibilización de requisito regulatorio: El 1 de abril, la Reserva Federal decidió excluir del coeficiente de apalancamiento complementario los títulos del Tesoro de los Estados Unidos y los depósitos en los bancos de la Reserva Federal. Esta decisión, que estará vigente hasta el 31 de marzo de 2021, se tomó para hacer frente al aumento de las reservas y el deterioro de las condiciones de liquidez en el mercado del Tesoro. En la declaración se decía que la Junta disponía esta exclusión temporal en la norma definitiva provisional a los efectos de que las instituciones bancarias pudieran ampliar sus balances según procediera para seguir actuando como intermediarios financieros, en lugar de aumentar las distribuciones de capital, y que aplicaría la norma final provisional en consecuencia.

El 9 de abril, la Reserva Federal anunció medidas nuevas y una ampliación de las ya existentes, con el objetivo de proporcionar hasta 2,3 billones de dólares en préstamos para apoyar la economíab:

Programa de liquidez del programa de protección de la nómina (Paycheck Protection Program Liquidity Facility (PPPLF)): Se otorga crédito a las instituciones financieras que conceden préstamos en el marco del programa de protección de la nómina (PPP) y que reúnen las condiciones necesarias. Para otorgar el crédito, los préstamos se toman como garantía al valor nominal. Se refuerza la eficacia del programa de protección de la nómina de la Agencia Federal para el Desarrollo de la Pequeña Empresa, al proporcionar liquidez a las instituciones financieras participantes mediante el financiamiento a plazo respaldado por préstamos que se otorgan a las pequeñas empresas en virtud de ese programac

Programa de préstamos para pequeñas y medianas empresas (Main Street Lending Program): Garantiza que las pequeñas y medianas empresas dispongan de crédito mediante la compra de hasta 600.000 millones de dólares en préstamos. El Departamento del Tesoro aportará 75.000 millones de dólares de capital a este servicio, y con ese fin recurrirá a los fondos de la Ley de Asistencia, Alivio y Protección Económica contra el Coronavirus (Coronavirus Aid, Relief, and Economic Security Act), conocida como Ley CARES. 
Programa de crédito para empresas en el mercado primario y secundario (PMCCF y SMCCF) y Programa de préstamo de valores a plazo respaldados por activos (TALF): Se ampliaron el tamaño y el alcance de los tres servicios para aumentar el crédito que llega a los hogares y las empresas a través de los mercados de capitales. Ahora, estos tres servicios permitirán otorgar hasta 850.000 millones de dólares en créditos, respaldados por una protección crediticia de 85.000 millones de dólares proporcionada por el Tesoro. Cabe destacar una modificación del programa de crédito para empresas en el mercado primario en virtud de la cual la Reserva Federal comprará deuda de alto rendimiento. La Reserva Federal podrá adquirir deudas de empresas que hayan sido calificadas con grado de inversión el 22 de marzo, pero que posteriormente hayan sido calificadas con un grado inferior al de inversión (siempre que sigan teniendo una calificación mínima de BB-/Ba3). También podrá comprar fondos de inversión negociados de bonos empresariales de alto rendimiento.

Programa de liquidez municipal (Municipal Liquidity Facility (MLF)): Ofrece hasta 500.000 millones de dólares en préstamos destinados a los estados y los municipios. El Tesoro aportará 35.000 millones de dólares de protección crediticia al servicio de liquidez municipal, y para ello recurrirá a los fondos asignados en la Ley CARES, que se examina en la siguiente sección.

El 27 de abril, la Junta de Gobernadores de la Reserva Federal anunció una ampliación del alcance y la duración del programa de liquidez municipal, para añadir nuevos umbrales de población que permitieran a un número considerablemente mayor de entidades pedir préstamos de forma directa a dicho servicio, en comparación con el número de entidades que podían hacerlo según el plan inicial anunciado el 9 de abril.

El 30 de abril, la Reserva Federal anunció la ampliación del alcance y los criterios de admisibilidad del programa de préstamos para pequeñas y medianas empresas. Entre las modificaciones se encontraban las siguientes: creación de una tercera opción de préstamo para los prestatarios que tenían más apalancamiento, opción que suponía una mayor distribución de los riesgos entre los prestamistas; reducción del tamaño mínimo de algunos préstamos hasta situarlo en 500.000 dólares, y ampliación del conjunto de empresas que podían solicitar préstamos. El 16 de junio, la Reserva Federal dijo que estaba estudiando cómo ampliar el programa de préstamos para pequeñas y medianas empresas a los efectos de incluir a las organizaciones sin fines de lucro.

El 16 de junio, el programa de crédito para empresas en el mercado secundario se amplió más allá de la compra de fondos de inversión negociados en los mercados bursátiles, como parte de un esfuerzo continuo por apoyar los mercados financieros y flexibilizar las condiciones de crédito. La Reserva Federal anunció que estaba comenzando a comprar bonos empresariales individuales por medio del programa.

El 28 de julio, la Reserva Federal anunció la extensión hasta el 31 de diciembre de siete programas cuya finalización estaba prevista para el 30 de septiembre o alrededor de esa fecha, a saber, el PDCF, el MMLF, el PMCCF, el SMCCF, el TALF, el PPPLF y el programa de préstamos para pequeñas y medianas empresas (Main Street Lending Program)

El 29 de julio, la Reserva Federal anunció que extendería hasta el 31 de marzo de 2021 sus líneas de canje de liquidez en dólares y el FIMA.

Fuente: Comisión Económica para América Latina y el Caribe (CEPAL), sobre la base de datos de la Reserva Federal y el Departamento del Tesoro de los Estados Unidos, y otras cifras oficiales.

a En otoño de 2019 la Reserva Federal ya había inyectado liquidez en el sistema, en un esfuerzo por resolver algunos problemas de liquidez derivados de la inestabilidad que había surgido en los mercados de los acuerdos de recompra el año pasado. En su decisión de enero de 2020 relativa a la tasa de interés, la Reserva Federal anunció que participaría en el mercado de los acuerdos de recompra hasta abril de 2020 como mínimo. Como resultado, la sección de la Reserva Federal que se encarga de las operaciones de mercado abierto (Open Market Desk) amplió sus operaciones relacionadas con los acuerdos de recompra a un día y a plazo para aumentar la liquidez en el mercado.

b Por medio de programas establecidos con arreglo al párrafo 3 del artículo 13 de la Ley de la Reserva Federal, estas medidas permitirían distribuir unos 195.000 millones de dólares de los 454.000 millones que el Congreso de los Estados Unidos consignó en la Ley de Asistencia, Alivio y Protección Económica contra el Coronavirus (Coronavirus Aid, Relief, and Economic Security Act), conocida como Ley CARES, que se examinará en la sección sobre política fiscal.

Mediante el programa de protección de la nómina se otorgan préstamos a las pequeñas empresas para que puedan mantener a sus trabajadores en la nómina. Este programa forma parte de la fase 3 de las medidas fiscales aprobadas por el Congreso, que se examinan en la sección sobre política fiscal.

\section{Herramientas nuevas y otras ya existentes}

La Reserva Federal también abrió su ventanilla de descuento a los bancos comerciales, redujo la tasa de crédito primario 150 puntos básicos (al 0,25\%), eliminó los encajes, restableció los acuerdos de líneas de intercambio de liquidez en dólares y amplió las operaciones de acuerdos de recompra (repos). Además, reintrodujo algunos programas financieros que se habían utilizado durante la crisis financiera y creó otros nuevos, con el fin de apoyar el flujo de crédito, en algunos casos con el respaldo del Tesoro de los Estados Unidos (véase el recuadro 1). 
Estos programas son: i) el programa de financiamiento de papeles comerciales (Commercial Paper Funding Facility (CPFF)), para facilitar la emisión de papeles comerciales por parte de empresas y municipios; ii) el servicio de crédito para operadores primarios (Primary Dealer Credit Facility (PDCF)), para reforzar la liquidez en los mercados financieros al permitir a ciertos operadores autorizados de deuda pública tomar prestado dinero en efectivo contra algunas existencias, deuda municipal y bonos empresariales de mayor calificación; iii) el programa de liquidez de fondos mutuos del mercado monetario (Money Market Mutual Fund Liquidity Facility (MMLF)), para poner a disposición de las instituciones financieras que reúnan las condiciones necesarias préstamos respaldados por activos de alta calidad comprados por las instituciones a fondos mutuos del mercado monetario, incluidos pagarés municipales a la vista de tasa variable y certificados de depósito bancarios; iv) el programa de préstamo de valores a plazo respaldados por activos (Term Asset-Backed Securities Loan Facility (TALF)), que da a la Reserva Federal la posibilidad de comprar valores negociables respaldados por préstamos para estudiantes, automóviles y tarjetas de crédito, así como préstamos a empresas a través de la Agencia Federal para el Desarrollo de la Pequeña Empresa; v) el programa de crédito para empresas en el mercado primario (Primary Market Corporate Credit Facility (PMCCF)), para adquirir nuevos bonos y préstamos de empresas; vi) el programa de crédito para empresas en el mercado secundario (Secondary Market Corporate Credit Facility (SMCCF)), para proporcionar liquidez para la adquisición de bonos empresariales en circulación; vii) el programa de acuerdo de recompra para autoridades monetarias extranjeras e internacionales (Repurchase Agreement Facility for Foreign and International Monetary Authorities, FIMA repo), que, junto con las líneas de canje de liquidez en dólares de los Estados Unidos, tiene por objeto ayudar a aliviar las tensiones en los mercados mundiales de financiamiento en dólares; viii) el programa de liquidez del programa de protección de la nómina (Paycheck Protection Program Liquidity Facility, PPPLF), para proporcionar liquidez a las instituciones financieras participantes que conceden préstamos a pequeñas empresas en el marco del programa de protección de la nómina (PPP) de la Agencia Federal para el Desarrollo de la Pequeña Empresa; ix) el programa de préstamos para pequeñas y medianas empresas (Main Street Lending Program), para asegurar los flujos de crédito a pequeñas y medianas empresas con la toma de hasta 600.000 millones de dólares en préstamos, y x) el programa de liquidez municipal (Municipal Liquidity Facility, MLF), que ofrece préstamos a los estados y municipios.

Aunque la Reserva Federal tiene una capacidad limitada para comprar activos y otorgar préstamos, en situaciones de emergencia, y con la autorización del Secretario del Tesoro (de conformidad con la sección 13(3) de la Ley de la Reserva Federal), puede agregar más programas de otorgamiento de préstamos para garantizar que las empresas puedan recibir préstamos de una manera que les resulte asequible y eficaz para sortear las crisis. El banco central no solo relanzó programas diseñados durante la crisis financiera de 2008-2009, sino que también creó cinco programas nuevos en respuesta a la pandemia (véase el cuadro 2)

Cuadro 2

Programas nuevos y ya existentes de la Reserva Federal utilizados en respuesta a la pandemia

\begin{tabular}{l|l}
\hline Programas nuevos & Programas ya existentes \\
\hline $\begin{array}{l}\text { Programa de crédito para empresas } \\
\text { en el mercado primario (PMCCF) }\end{array}$ & $\begin{array}{l}\text { Programa de financiamiento de papeles } \\
\text { comerciales (CPFF) }\end{array}$ \\
\hline $\begin{array}{l}\text { Programa de crédito para empresas } \\
\text { en el mercado secundario (SMCCF) }\end{array}$ & $\begin{array}{l}\text { Servicio de crédito para operadores } \\
\text { primarios (PDCF) }\end{array}$ \\
\hline $\begin{array}{l}\text { Programa de acuerdo de recompra para } \\
\text { autoridades monetarias extranjeras } \\
\text { e internacionales (FIMA) }\end{array}$ & $\begin{array}{l}\text { Programa de liquidez de fondos mutuos } \\
\text { del mercado monetario (MMLF) }\end{array}$ \\
\hline $\begin{array}{l}\text { Programa de liquidez del programa } \\
\text { de protección de la nómina (PPPLF) }\end{array}$ & $\begin{array}{l}\text { Programa de préstamo de valores a plazo } \\
\text { respaldados por activos (TALF) }\end{array}$ \\
\hline
\end{tabular}

Fuente: Comisión Económica para América Latina y el Caribe (CEPAL), sobre la base de datos de la Reserva Federal de los Estados Unidos.

Nota: Los programas ya existentes son herramientas que se utilizaron en respuesta a la crisis financiera de 2008-2009. 
En términos generales, los programas y las medidas adoptadas por la Reserva Federal tienen como finalidad apoyar el funcionamiento del mercado financiero, alentar a los bancos a conceder préstamos, apoyar a las empresas y los negocios, brindar asistencia a los hogares y los consumidores, apoyar los préstamos estatales y municipales, y amortiguar las presiones internacionales sobre los mercados monetarios de los Estados Unidos (véase el cuadro 3)

Cuadro 3

Medidas y programas nuevos y ya existentes de la Reserva Federal, por objetivo

1. Apoyar el funcionamiento del mercado financiero

2. Alentar a los bancos a conceder préstamos

3. Apoyar a las empresas y los negocios

4. Brindar asistencia a los hogares y los consumidores

5. Apoyar los préstamos estatales y municipales

6. Amortiguar las presiones internacionales
Compras de títulos (expansión cuantitativa) - abiertas

Préstamos a empresas de títulos: Servicio de crédito para operadores primarios (PDCF)

Respaldar fondos mutuos del mercado monetario: Programa de liquidez de fondos mutuos del mercado monetario (MMLF)

Operaciones repo

Préstamos directos a bancos (ventanilla de descuento)

Flexibilización de requisitos regulatorios: encaje, capacidad total de absorción de pérdidas y coeficiente de apalancamiento complementario

Préstamos directos a grandes empleadores: Programa de crédito para empresas en el mercado primario (PMCCF), Programa de crédito para empresas en el mercado secundario (SMCCF) Respaldar el mercado de papeles comerciales: Programa de financiamiento de papeles comerciales (CPFF)

Respaldar préstamos a pequeñas y medianas empresas: Programa de liquidez del programa de protección de la nómina (PPPLF), Programa de préstamos para el sector comercial

Programa de préstamo de valores a plazo respaldados por activos (TALF)

Préstamos directos: Programa de liquidez municipal (MLF)

Respaldar la liquidez de los bonos: utilización del Programa de liquidez de fondos mutuos del mercado monetario (MMLF) y el Programa de financiamiento de papeles comerciales (CPFF) para respaldar los mercados de deuda municipal.

Líneas de intercambio de divisas

Programa de acuerdo de recompra para autoridades monetarias extranjeras e internacionales (FIMA), que ofrece dólares a bancos centrales que no cuentan con una línea de intercambio de divisas

Fuente: Comisión Económica para América Latina y el Caribe (CEPAL), sobre la base de datos de la Reserva Federal de los Estados Unidos y J. Cheng, D. Skidmore y D. Wessel, "What's the Fed doing in response to the COVID-19 crisis? What more could it do?", The Brookings Institution, 9 de abril de 2020 [en línea] https://www.brookings.edu/research/fed-response-to-covid19/.

\section{B. La política fiscal}

Al igual que en el caso de la política monetaria, la velocidad con la que se han aplicado las medidas fiscales no tiene precedentes. Durante la crisis financiera mundial se necesitaron más de 500 días para que todas las medidas fiscales entraran en vigor. Esta vez, en respuesta a la pandemia, el Congreso de los Estados Unidos aprobó tres leyes solo en el mes de marzo (véase el gráfico 15).

El Congreso ha aprobado cinco leyes de estímulo en respuesta al COVID-19: tres paquetes fiscales y dos medidas complementarias. Juntos equivalen al $13 \%$ del PIB

\section{Fase uno: ley de consignaciones complementarias para la preparación y respuesta ante el coronavirus (Coronavirus Preparedness and Response Supplemental Appropriations Act), 6 de marzo de 2020}

La primera fase comprendía 8.300 millones de dólares en gastos de emergencia destinados a los organismos federales que combatían la propagación de la enfermedad. Ese importe incluía lo siguiente: 3.400 millones de dólares dirigidos al Fondo de Emergencia de Salud Pública y Servicios Sociales a fin de que se investigaran y desarrollaran nuevas vacunas, tratamientos y diagnósticos; 1.900 millones de dólares asignados a los Centros para el Control y la Prevención de Enfermedades a fin de respaldar la labor de respuesta de los gobiernos estatales y locales, y 1.600 millones de dólares en asistencia internacional. 
Gráfico 15

Estados Unidos: total de fondos autorizados por el Congreso, 2008-2009 y 2020

(En miles de millones de dólares)

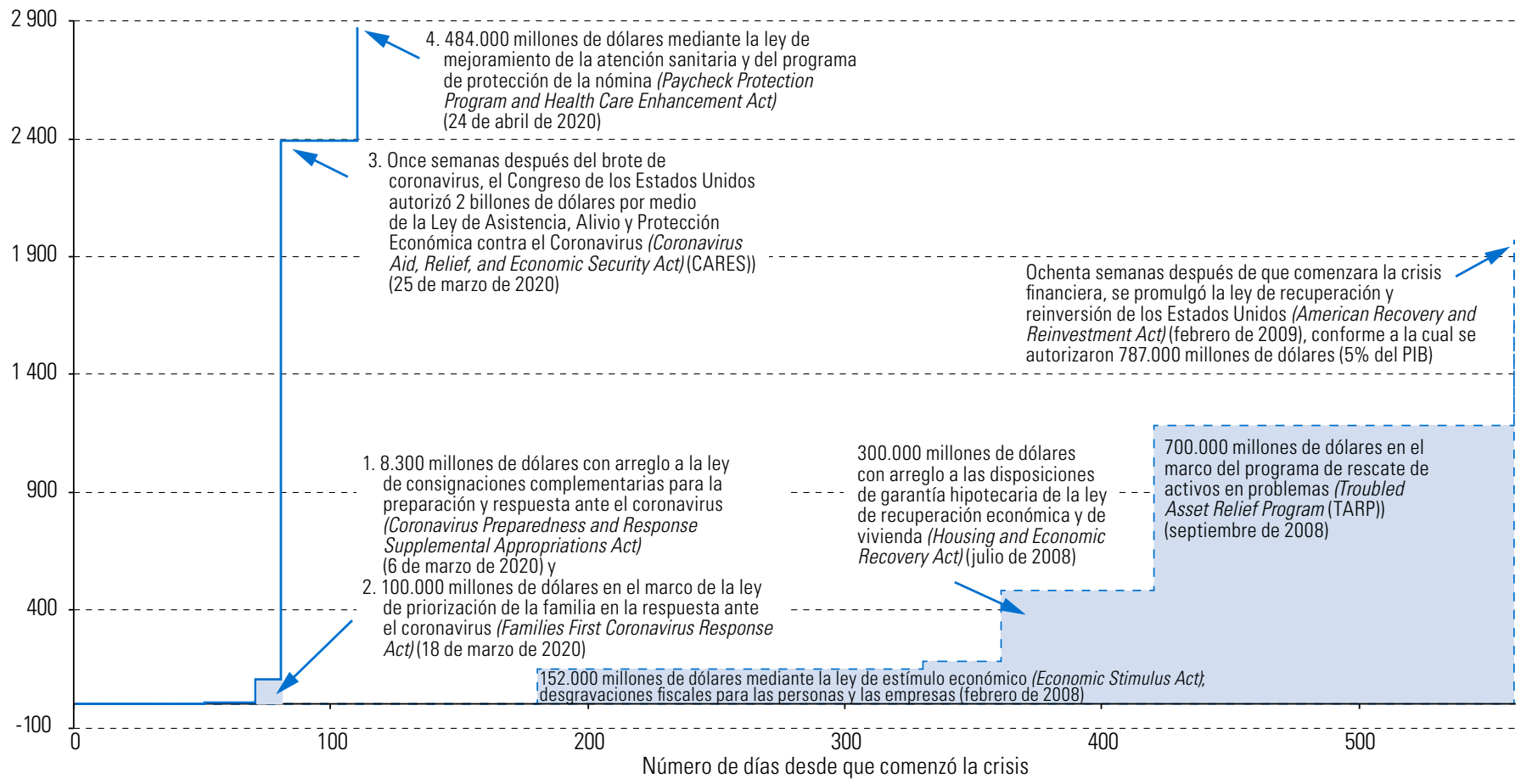

_-_ Desde que surgieron los primeros indicios de una crisis financiera (7 de agosto de 2007)

— Desde que China informó de la primera muerte por COVID-19 (11 de enero de 2020)

Fuente: Comisión Económica para América Latina y el Caribe (CEPAL), sobre la base de estimaciones de la Oficina de Presupuesto del Congreso y otras estimaciones oficiales, y de J. M. Schlesinger y H. Sender, "How fast the economy crashed and Washington responded -in charts", Wall Street Journal, 27 de marzo de 2020 [en línea] https://www.wsj.com/articles/how-fast-the-economy-crashed-and-washington-respondedincharts-11585334137.

Nota: Los primeros indicios de la crisis financiera surgieron en agosto de 2007, cuando los valores negociables respaldados por hipotecas de alto riesgo se desplomaron.

\section{Fase dos: ley de priorización de la familia en la respuesta ante el coronavirus (Families First Coronavirus Response Act), 18 de marzo de 2020}

En esta segunda ley importante se preveían licencias de enfermedad con goce de sueldo, asistencia alimentaria para las poblaciones vulnerables y ayuda financiera destinada a las pruebas del coronavirus. Se ofrecía la posibilidad de hacerse pruebas gratuitas para detectar el COVID-19 y se exigía a los empleadores más pequeños que otorgaran al menos dos semanas de licencia de enfermedad con goce de sueldo a muchos de los afectados por la crisis. También se aumentaron los fondos destinados al programa Medicaid, se amplió el seguro de desempleo y se dispuso más dinero para cupones de alimentos, en un esfuerzo por proporcionar una red de protección social básica para cuando los despidos y los casos de COVID-19 comenzaran a causar un impacto en todos los estados. En conjunto, la asistencia financiera movilizada en la primera y la segunda fase equivalía al 0,5\% del PIB

Fase tres: Ley de Asistencia, Alivio y Protección Económica contra el Coronavirus
(Coronavirus Aid, Relief, and Economic Security Act (CARES)), 27 de marzo de 2020

Los legisladores se refieren a esta ley como la fase 3 de la respuesta del Congreso ante el coronavirus, tras la ley de consignaciones complementarias para la preparación y respuesta ante el coronavirus (6 de marzo de 2020) y la ley de priorización de la familia en la respuesta ante el coronavirus (18 de marzo de 2020). Esta tercera fase tenía por objeto mitigar el daño infligido por la pandemia. 
En esta ley se disponen más de 2 billones de dólares (alrededor del 11\% del PIB) para nuevos gastos y desgravaciones fiscales, lo que la convierte en el mayor paquete de rescate de la historia de los Estados Unidos. Las principales disposiciones de la Ley CARES son las siguientes: i) 290.000 millones de dólares para entregar cheques a las personas por una única vez; ii) 260.000 millones de dólares para ampliar las prestaciones de desempleo; iii) 25.000 millones de dólares en asistencia alimentaria; iv) 510.000 millones de dólares para evitar la quiebra de empresas mediante la concesión de préstamos y garantías de préstamos, y para respaldar los programas de la Reserva Federal de acuerdo al párrafo 3 del artículo 13 de la Ley de la Reserva Federal; v) 367.000 millones de dólares en garantías y préstamos condonables de la Agencia Federal para el Desarrollo de la Pequeña Empresa, a fin de prestar ayuda a las pequeñas empresas que retengan a sus trabajadores; vi) 180.000 millones de dólares para los hospitales y la atención de la salud; vii) 150.000 millones de dólares en transferencias a los gobiernos estatales y locales; viii) más de 100.000 millones de dólares en fondos para la educación, los sistemas de tránsito y la asistencia internacional, y ix) 280.000 millones de dólares en reducciones, aplazamientos y diferimientos tributarios (véanse el diagrama 1 y el recuadro 2).

La magnitud de la pandemia ha ejercido presión sobre los recursos internos de los Estados Unidos y, al mismo tiempo, sobre la asistencia internacional. Aunque la mayor parte de la Ley CARES se refiere a la respuesta y el socorro internos, en ella también se incluyen algunos fondos complementarios de ayuda exterior y autorizaciones pendientes para que las instituciones financieras internacionales apoyen la respuesta internacional. También se proporcionan fondos de ayuda exterior como parte de la ley complementaria inicial (véase el recuadro 3).

\section{Diagrama 1}

Estados Unidos: fase tres de las medidas de estímulo, que representan más de 2 billones de dólares

(En miles de millones de dólares)

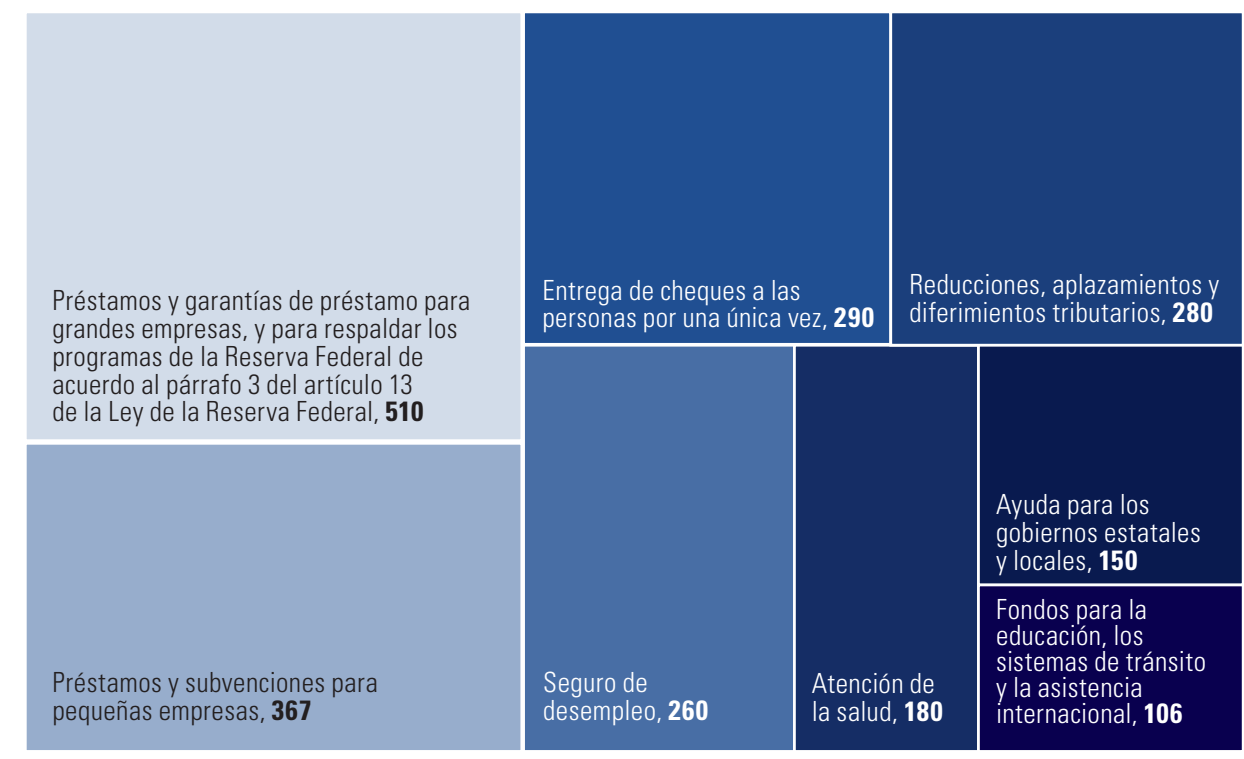

Fuente: Comisión Económica para América Latina y el Caribe (CEPAL), sobre la base de estimaciones del Fondo Monetario Internacional (FMI) y Moody's Analytics. 
Recuadro 2

Ley de Asistencia, Alivio y Protección Económica contra el Coronavirus (Coronavirus Aid, Relief, and Economic Security Act (CARES)), 27 de marzo de 2020

Entre las principales disposiciones de la Ley CARES se encuentran las siguientes:

\section{Medidas de apoyo a los hogares}

Pagos en efectivo: Unos 300.000 millones de dólares en total. En la Ley se prevén pagos directos de 1.200 dólares por adulto (más 500 dólares por niño) para quienes tengan ingresos anuales brutos inferiores a 75.000 dólares (150.000 dólares en el caso de las parejas que presentan sus declaraciones de forma conjunta). Los subsidios directos se van reduciendo gradualmente para los grupos de ingresos más altos y no están disponibles para las personas sin hijos que ganen más de 99.000 dólares anuales, ni para las parejas casadas sin hijos que ganen más de 198.000 dólares anuales. Los pagos se estructuran como reembolsos de impuestos para que el Servicio de Impuestos Internos (IRS) pueda distribuir los fondos rápidamente.

Subsidio de desempleo: 260.000 millones de dólares para aumentar la cantidad de personas que pueden acogerse a los programas estatales de seguro de desempleo dirigidos a los trabajadores, entre ellos, los autónomos, que han sido afectados negativamente por el COVID-19 (incluidos los que tienen un familiar enfermo o un hijo que no puede asistir a la escuela). Las prestaciones se proporcionarán durante un período máximo de cuatro meses (hasta el 31 de julio). En la Ley CARES se prolonga de 26 a 29 semanas el período durante el cual se otorgan las prestaciones en la mayoría de los estados y se prevé, además, un pago complementario de 600 dólares por semana destinado a quienes reúnan las condiciones para recibir la asistencia.

Asistencia alimentaria: 25.000 millones de dólares para programas de nutrición infantil y más fondos para los cupones de alimentos del Programa de Asistencia Nutricional Suplementaria (Supplemental Nutrition Assistance Program (SNAP)).

Distribuciones de fondos de jubilación con ventajas fiscales: Se permitirá a las personas hacer una distribución relacionada con el coronavirus de hasta 100.000 dólares sin penalización.

Diferimiento de impuestos: Los plazos para las personas que presentan declaraciones de impuestos se aplazaron de abril a julio. Medidas de apoyo a las empresas

Asistencia para los sectores gravemente afectados: Más de 500.000 millones de dólares destinados a préstamos, garantías de préstamos u otras ayudas dirigidas a las empresas, incluida la posibilidad de que el Gobierno participe directamente en el capital de las empresas afectadas. La asistencia comprende 25.000 millones de dólares para las empresas de transporte aéreo de pasajeros, 4.000 millones de dólares para las empresas de transporte aéreo de carga, 17.000 millones de dólares para las empresas consideradas fundamentales para la seguridad nacional, y el resto para respaldar los servicios ofrecidos con arreglo al párrafo 3 del artículo 13 de la Ley de la Reserva Federal en el marco de los cuales se adquieren obligaciones empresariales en el mercado primario o el secundario (454.000 millones de dólares).

Se pedirá a las empresas que reciban garantías de préstamo o préstamos directos que limiten la remuneración de los ejecutivos a 425.000 dólares al año y que no lleven a cabo recompras de acciones durante al menos un año. Las empresas que sean propiedad del Presidente, el Vicepresidente, los miembros del Congreso o los jefes de organismos federales no podrán recibir apoyo. Esta asistencia empresarial será supervisada por un inspector general independiente y un panel de supervisión del Congreso

Asistencia para las pequeñas empresas otorgada mediante el programa de protección de la nómina (Paycheck Protection Program (PPP)): Unos 367.000 millones de dólares en préstamos y garantías de la Agencia Federal para el Desarrollo de la Pequeña Empresa, dirigidos a empresas que tengan hasta 500 empleados (incluidos los contratistas independientes y los trabajadores por cuenta propia), para cubrir los costos de la nómina, los pagos de las hipotecas y los alquileres, los servicios públicos y las prestaciones para servicios médicos. Se deben entregar anticipos de emergencia correspondientes a estos préstamos dentro de los tres días siguientes a la solicitud, y el total del préstamo puede ser de hasta el 250\% de la nómina mensual. Los préstamos podrán ser objeto de una condonación parcial o total según la medida en que la empresa mantenga en nómina el número de empleados que tenía antes de la crisis

Aplazamiento del impuesto sobre la nómina: Se permitirá a las empresas aplazar sus obligaciones en materia del impuesto sobre la nómina durante el resto del año, y estas se pagarán a plazos en 2021/2022.

Desgravación fiscal por retención de empleados: Esta desgravación proporcionará incentivos a las empresas para que mantengan a los trabajadores en sus nóminas.

Diferimiento del plazo de los impuestos: Las empresas podrán diferir sus pagos trimestrales de impuestos estimados hasta después del 15 de octubre de 2020 y aplazar los pagos de los impuestos sobre la nómina hasta el final del año.

\section{Otras disposiciones}

$\mathbf{1 8 0 . 0 0 0}$ millones de dólares para gastos de atención de la salud: De ese dinero, 100.000 millones de dólares se destinarán a otorgar financiamiento a los hospitales y los prestadores de asistencia sanitaria que hayan sido más afectados por la pandemia. El dinero podría utilizarse con el propósito de adquirir equipos de protección personal para los trabajadores de la salud e insumos para realizar pruebas, así como para financiar centros de operaciones de emergencia. En la Ley se aumentan los fondos que se destinan a los centros de salud comunitarios, los pagos del programa Medicare, los servicios 
de telemedicina y a domicilio, y los organismos de salud pública. También se dispone una serie de medidas para hacer frente a la insuficiencia actual de suministros médicos y para evitar que haya escasez en el futuro, incluso mediante la Ley de Producción de Defensa (Defense Production Act).

$\mathbf{1 5 0 . 0 0 0}$ millones de dólares en transferencias a los gobiernos estatales y locales para hacer frente a los déficits de gasto relacionados con la pandemia. Se distribuirán según el tamaño de la población. Un municipio podrá solicitar que se le brinde ayuda directamente, lo que reducirá la cantidad disponible para el resto del estado.

$\mathbf{5 0 . 0 0 0 ~ m i l l o n e s ~ d e ~ d o ́ l a r e s ~ e n ~ a s i s t e n c i a ~ i n t e r n a c i o n a l . ~}$

$\mathbf{3 1 . 0 0 0}$ millones de dólares en fondos para la educación destinados a apoyar las escuelas y universidades locales, y a dar un tratamiento más flexible a la ayuda financiera y los préstamos para estudiantes.

$\mathbf{2 5 . 0 0 0}$ millones de dólares para los sistemas de tránsito a fin de compensar la pérdida de ingresos debida a la disminución del número de pasajeros.

Fuente: Comisión Económica para América Latina y el Caribe (CEPAL), sobre la base de estimaciones del Fondo Monetario Internacional (FMI) y Moody's Analytics.

\section{Recuadro 3}

Fondos de ayuda exterior

Según los datos del Servicio de Investigaciones del Congreso (CRS), el Congreso de los Estados Unidos ha consignado casi 1.800 millones de dólares en fondos de asistencia exterior de emergencia mediante dos leyes de consignaciones complementarias para hacer frente a los efectos del COVID-19. La primera ronda de fondos de ayuda complementaria es la que se otorgó en la Ley Pública 116-123, que se promulgó el 6 de marzo y forma parte de la ley de consignaciones complementarias para la preparación y respuesta ante el coronavirus (Coronavirus Preparedness and Response Supplemental Appropriations Act) Esta primera ronda estuvo centrada en reponer los fondos de asistencia sanitaria de emergencia y para desastres que ya se habían agotado por las actividades de respuesta ante el COVID-19. También incluía fondos destinados a satisfacer necesidades económicas, de seguridad y de estabilización relacionadas con la pandemia. Por medio de la segunda ley de consignaciones complementarias en que se suministraban fondos de ayuda exterior (la Ley Pública 116-136, que se promulgó el 27 de marzo y formaba parte de la Ley CARES) se dispuso asistencia adicional para el exterior y para hacer frente al COVID-19. Según Brown, Lawson y Morgenstern (2020), ante la iniciativa pangubernamental en curso para hacer frente a la pandemia en los Estados Unidos, el Congreso evalúa continuamente si los fondos deben apoyar la respuesta a la pandemia en el extranjero, o si esos recursos deben centrarse en las necesidades de respuesta en los Estados Unidos.

Fuente: Comisión Económica para América Latina y el Caribe (CEPAL), sobre la base de información del Servicio de Investigaciones del Congreso y de N. Brown, M. Lawson y E. Morgenstern, "COVID-19 and foreign assistance: issues for Congress", In Focus, N 11496, Servicio de Investigaciones del Congreso, 6 de abril de 2020

El Congreso también aprobó nuevas leyes en abril y junio para aumentar la eficacia de los programas incluidos en los tres paquetes fiscales anteriores, y la del programa de protección de la nómina en particular. El 24 de abril de 2020 se promulgó la ley de mejoramiento de la atención sanitaria y del programa de protección de la nómina (Paycheck Protection Program and Health Care Enhancement Act), mediante la cual se inyectaron 484.000 millones de dólares más en la labor de socorro ante el coronavirus. Ese importe se distribuyó de la siguiente manera: i) 322.000 millones de dólares de financiamiento adicional para el programa de protección de la nómina, el programa de préstamos para pequeñas empresas que alcanzó rápidamente su límite anterior (de esa cifra, 60.000 millones de dólares se reservarían de forma específica para prestamistas pequeños, medianos y comunitarios); ii) 60.000 millones de dólares para préstamos y subsidios destinados a las pequeñas empresas en caso de desastre, a saber, el fondo de préstamos para desastres que causan perjuicios económicos (Economic Injury Disaster Loan); iii) 75.000 millones de dólares para los hospitales, y iv) 25.000 millones de dólares para las pruebas de coronavirus

Mediante la ley sobre la flexibilización del programa de protección de la nómina (Paycheck Protection Program Flexibility Act), que se promulgó el 5 de junio de 2020, se modifica el programa de protección de la nómina de la Ley CARES para dar a los prestatarios más libertad en cuanto a la forma y el momento en que gastan los fondos del préstamo, sin perder la posibilidad de obtener una condonación total. Las principales 
modificaciones son las siguientes: extensión a 24 semanas del período para gastar lo obtenido en virtud del préstamo (el período anterior era de 8 semanas); reducción al 60\% de la parte del préstamo que es obligatorio gastar en la nómina (la proporción anterior era del $75 \%)$; dos nuevas excepciones que permiten a los prestatarios obtener la condonación total incluso sin restaurar por completo su fuerza de trabajo; extensión a cinco años del plazo para devolver el préstamo (el plazo original era de dos años), y una nueva medida que permite a las empresas diferir el pago de los impuestos de la nómina, aunque hayan recibido un préstamo en el marco del programa de protección de la nómina?

Sin embargo, se avecinan fechas límite importantes y hay programas que se agotarán en las próximas semanas y meses. Los subsidios de desempleo adicionales (el pago complementario de 600 dólares por semana en virtud de la Ley CARES), por ejemplo, se dejaron de otorgar el 31 de julio. Cada fecha de vencimiento pondrá a prueba la recuperación, que todavía es frágil. Corresponde ahora a los legisladores decidir cuánto más estímulo podría necesitar la economía de los Estados Unidos para avanzar, y qué forma debería adoptar

\section{Desafíos a largo plazo}

- ¿Qué tipo de recuperación económica tendrá lugar después del coronavirus? Existe una gran incertidumbre en cuanto al momento en que la recuperación económica tendrá lugar y respecto de la forma que esta adoptará: V, U, L o alguna otra forma. La recuperación probablemente dependerá de la duración de la crisis. Según el Expresidente de la Reserva Federal, Ben Bernanke, la duración de la crisis provocada por la pandemia es el factor decisivo que determinará cuán grave va a ser y cuánta huella dejará en la economía de los Estados Unidos. Cuanto más tiempo dure, más empresas quebrarán y cerrarán sus puertas. Cuanto más tiempo dure, más gente perderá su trabajo y perderá la relación con sus antiguos empleadores. Cuanto más tiempo dure, más destrucción habrá y más difícil será recuperarse. Es por eso que la duración va a ser decisiva. El factor que más incidirá en la duración será la respuesta sanitaria (The Brookings Institution, 2020). En el informe semestral de política monetaria que se presentó al Congreso el 16 de junio, el actual Presidente de la Reserva Federal, Jerome Powell, añadió que el factor que más pesaba sobre las perspectivas era la incertidumbre sobre la trayectoria de la enfermedad y los efectos de las medidas destinadas a contenerla (Junta de Gobernadores de la Reserva Federal, 2020b).

- De responder a la emergencia a fomentar la recuperación. La Reserva Federal ha actuado con prontitud y energía, como primera línea de defensa en lo que atañe a la liquidez y el mantenimiento del orden en los mercados. Su balance se ha expandido rápidamente desde marzo, ya que ha puesto en práctica una expansión cuantitativa abierta para comprar tantos títulos del Tesoro y títulos con garantía hipotecaria como sean necesarios. Sin embargo, el juego de herramientas de la Reserva Federal —que comprende tasas de interés que ya son muy bajas - es más limitado en lo que respecta a estimular el crecimiento. La Reserva Federal es el prestamista de última instancia, pero no controla el gasto fiscal. Según el Presidente de la Reserva Federal, es posible que el Gobierno deba gastar más para contribuir a que la economía se recupere después de la contracción provocada por el coronavirus, y para evitar que los hogares y las empresas caigan en la insolvencia, lo que podría pesar sobre el crecimiento en los años venideros. Añadió que, si bien sería costoso, valdría la pena ofrecer más estímulos si estos ayudaran a evitar que la crisis del COVID-19 provocara un daño económico a largo plazo. Además, en sus observaciones de junio ante el Congreso, Powell subrayó que la carga de la recesión causada por el COVID-19 no había recaído por igual en todos los estadounidenses, pues había tenido un efecto desproporcionado en los hogares de bajos ingresos. Dijo que, si no se contiene y revierte, la recesión podría ampliar aún más las brechas de bienestar económico que el largo período de crecimiento había contribuido en algo a cerrar.

Dos meses después del inicio del programa de protección de la nómina se han entregado más de 530.000 millones de dólares a 4,5 millones de empresas y se cree que el programa ha tenido un efecto estabilizador en la economía de los Estados Unidos. 
- ¿Importa que crezca la carga de la deuda? Como resultado de la pandemia y de las medidas adoptadas para hacer frente a sus efectos económicos, se prevé que el déficit y la deuda federales aumenten considerablemente. La Oficina de Presupuesto del Congreso estima que la deuda federal en poder del público será del 101\% del PIB a finales del ejercicio económico 2020 y crecerá hasta representar un 108\% del PIB a finales de 2021, frente al 79\% que representaba a finales del año fiscal 2019. Si bien la opinión general es que este es el precio que debe pagarse para hacer frente a los efectos del COVID-19, y que las bajas tasas de interés significan que el mayor nivel de deuda podría ser sostenible, un aumento de la carga de la deuda podría plantear problemas importantes a mediano y largo plazo, entre ellos, tensiones intergeneracionales.

- ¿Se ha sacrificado demasiado la resiliencia a cambio de la eficiencia? La pandemia de COVID-19 ha revelado que la cadena de suministro presenta vulnerabilidades graves en sectores clave de la economía mundial, en particular en la cadena de suministros médicos. Mientras las autoridades y los sectores económicos evalúan los beneficios y los costos de contar con cadenas de suministro globalizadas, y determinan si se han vuelto demasiado dependientes de unos pocos proveedores, se podrían buscar diversas formas de fomentar la resiliencia. La diversificación de las cadenas de suministro y su relocalización dentro de las fronteras nacionales parecen ser opciones plausibles.

\section{Bibliografía}

Adrian, T. y F. Natalucci (2020), "La crisis de la COVID-19 es una amenaza para la estabilidad financiera”, Diálogo a Fondo, 14 de abril [en línea] https://blog-dialogoafondo.imf. $\operatorname{org} / \mathrm{p}=13195$

Automotive News (2020), "Mexico asks U.S., Canada to grant automakers transition for USMCA rules", 6 de abril [en línea] https://www.autonews.com/automakers-suppliers/mexicoasks-us-canada-grant-automakers-transition-usmca-rules.

BLS (Oficina de Estadísticas Laborales de los Estados Unidos) (2020a), The Employment Situation - April 2020, Washington, D.C.

(2020b), The Employment Situation - May 2020, Washington, D.C.

(2020c), The Employment Situation - June 2020, Washington, D.C.

(2020d), "Current Employment Statistics" [en línea] https://www.bls.gov/ces/.

Borjas, G. J. y H. Cassidy (2020), "The adverse effect of the COVID-19 labor market shock on immigrant employment", Discussion Paper Series, $N^{\circ} 13277$, Bonn, Institute for Labor Economics (IZA), mayo.

Bown, C. P. (2020), "COVID-19: Trump's curbs on exports of medical gear put Americans and others at risk", Peterson Institute for International Economics, 9 de abril [en línea] https:// www.piie.com/blogs/trade-and-investment-policy-watch/covid-19-trumps-curbs-exportsmedical-gear-put-americans-and.

Brinca, P., J. B. Duarte y M. Faria e Castro (2020), "Is the COVID-19 pandemic a supply or a demand shock?", Economic Synopses, N 31, Banco de la Reserva Federal de St. Louis.

Brown, N., M. Lawson y E. Morgenstern (2020), "COVID-19 and foreign assistance: issues for Congress", In Focus, N 11496, Servicio de Investigaciones del Congreso, 6 de abril.

CEPAL (Comisión Económica para América Latina y el Caribe) (2020), "Las restricciones a la exportación de productos médicos dificultan los esfuerzos por contener la enfermedad por coronavirus (COVID-19) en América Latina y el Caribe", Informes COVID-19, Santiago, mayo.

Cheng, J., D. Skidmore y D. Wessel (2020), "What's the Fed doing in response to the COVID-19 crisis? What more could it do?", The Brookings Institution, 9 de abril [en línea] https:// www.brookings.edu/research/fed-response-to-covid19/

Departamento de Agricultura (2020), "USDA announces Coronavirus Food Assistance Program", Press Release, $\mathrm{N}^{\circ}$ 0222.20, 17 de abril [en línea] https://www.usda.gov/media/pressreleases/2020/04/17/usda-announces-coronavirus-food-assistance-program. 
Diálogo Interamericano (2020), "Impact of the COVID-19 pandemic on migrants and remittances to Latin America and the Caribbean", 13 de abril [en línea] https://www.thedialogue. org/analysis/impact-of-the-covid-19-pandemic-on-migrants-and-remittances-to-latinamerica-and-the-caribbean/.

FAO (Organización de las Naciones Unidas para la Alimentación y la Agricultura) (2020), Los trabajadores migrantes y la pandemia de COVID-19, Roma, 23 de abril.

Gagnon, J. (2020), "COVID-19: consequences for international migration and development", Development Matters, Organización de Cooperación y Desarrollo Económicos (OCDE), 2 de abril [en línea] https://oecd-development-matters.org/2020/04/02/covid-19consequences-for-international-migration-and-development/.

García Mora, A. y M. Rutkowski (2020), "Mantener los flujos de remesas en tiempos del coronavirus (COVID-19)", Blog de Datos, Banco Mundial, 3 de abril [en línea] https://blogs.worldbank. org/es/datos/mantener-los-flujos-de-remesas-en-tiempos-del-coronavirus.

González, A. (2020), "Yes, medical gear depends on global supply chains. Here's how to keep them moving", Peterson Institute for International Economics, 27 de marzo [en línea] https://www. piie.com/blogs/trade-and-investment-policy-watch/yes-medical-geardepends-global-supply-chains-heres-how-keep.

Junta de Gobernadores de la Reserva Federal (2020a), "Industrial production and capacity utilization", Federal Reserve Statistical Release, Washington, D.C.

(2020b), "Semiannual Monetary Policy Report to the Congress", Washington, D.C., 16 de junio [en línea] https://www.federalreserve.gov/newsevents/testimony/powell20200616a.htm.

Naciones Unidas (2020), UN Comtrade - Base de Datos Estadísticos sobre el Comercio Internacional [en línea] https://comtrade.un.org/ [fecha de consulta: 14 de agosto de 2020]

NBER (Oficina Nacional de Investigaciones Económicas) (2020), "The NBER's Recession Dating Procedure" [en línea] https://www.nber.org/cycles/recessions.pdf.

Ocampo, J. A. (2020), "Economías emergentes: hoja de ruta para manejar financiamiento y deuda", El Tiempo, 7 de junio [en línea] https://www.eltiempo.com/mundo/economias-emergenteshoja-de-ruta-para-manejar-financiamiento-y-deuda-en-los-paises-emergentes-504170.

Oficina de Aduanas y Protección Fronteriza (2019), "U.S. Border patrol southwest border apprehensions by sector fiscal year 2019: southwest border unaccompanied alien children (0-17yr old) apprehensions", 14 de noviembre [en línea] https://www.cbp.gov/newsroom/ stats/sw-border-migration/usbp-sw-border-apprehensions-fy2019 [fecha de consulta: 14 de agosto de 2020]

Oficina de Estadísticas Laborales de los Estados Unidos (2020), "Current Employment Statistics" [en línea] https://www.bls.gov/ces/.

Oficina del Censo de los Estados Unidos (2020), "Advance monthly sales for retail and food services, July 20", 14 de agosto [en línea] https://www.census.gov/retail/marts/www/ marts_current.pdf.

OMC (Organización Mundial del Comercio) (2020), "Trade set to plunge as COVID-19 pandemic upends global economy", Press Release, N 855, 8 de abril [en línea] https://www.wto. org/english/news_e/pres20_e/pr855_e.htm.

OMT (Organización Mundial del Turismo) (2020), UNWTO Tourism Data Dashboard [base de datos en línea] https://www.unwto.org/es/unwto-tourism-dashboard [fecha de consulta: 20 de junio].

Reinsch, W., J. Caporal y S. Tuljapurka (2020), "Trade symptoms of the pandemic", de Estudios Estratégicos e Internacionales (CSIS), 3 de abril [en línea] https://www.csis.org/analysis/ trade-symptoms-pandemic

Reuters (2020), "Mexico auto production, exports nosedive as coronavirus bites", 6 de abril [en línea] https://www.reuters.com/article/mexico-autos-idUSL1N2BU16P.

Richter, F. (2020), "Economic impact of COVID-19: U.S. car industry most reliant on Chinese parts", 21 de febrero [en línea] https://www.statista.com/chart/20913/chinese-exportsof-motor-vehicle-parts-and-accessories/

Rogoff, K. (2020), "Mapping the COVID-19 recession", Project Syndicate, 7 de abril.

Schlesinger, J. M. y H. Sender (2020), "How fast the economy crashed and Washington responded -in charts", Wall Street Journal, 27 de marzo [en línea] https://www.wsj.com/articles/ how-fast-the-economy-crashed-and-washington-respondedin-charts-11585334137.

Sutter, K., M. Sutherland y A. Schwarzenberg (2020), "COVID-19: China medical supply chains and broader trade issues", CRS Report, $N^{\circ}$ R46304, Servicio de Investigaciones del Congreso, 6 de abril. 
The Brookings Institution (2020), "Webinar: Former Fed Chair Ben Bernanke weighs in on the economic response to COVID-19", Washington, D.C., 7 de abril [en línea] https://www. brookings.edu/events/webinar-former-fed-chair-ben-bernanke-weighs-in-on-the-economicresponse-to-covid-19/.

The Economic Club of New York (2020), "Ambassador Robert Lighthizer: United States Trade Representative", 4 de junio [en línea] https://www.econclubny.org/ documents/10184/109144/2020LighthizerTranscript.pdf.

White, D. y B. Yaros (2020), "A stimulus to remember", Moody's Analytics, 30 de marzo [en línea] https://www.economy.com/economicview/analysis/378887/A-Stimulus-to-Remember.

Zarroli, J. y A. Schneider (2020), "Jobs carnage mounts: 17 million file for unemployment in 3 weeks", NPR, 9 de abril [en línea] https://www.npr.org/sections/coronavirus-liveupdates/2020/04/09/830216099/6-6-million-more-file-for-unemployment-as-coronaviruskeeps-economy-shut.

Este documento es parte de un conjunto de informes elaborados por la Comisión Económica para América Latina y el Caribe (CEPAL) sobre la evolución y los efectos de la pandemia de COVID-19 en América Latina y el Caribe. Fue preparado por la oficina de la CEPAL en Washington, D.C., dirigida por Inés Bustillo, bajo la coordinación general de Alicia Bárcena, Secretaria Ejecutiva, y Mario Cimoli, Secretario Ejecutivo Adjunto de la CEPAL.

Copyright (C) Naciones Unidas, 2020

E I I Economic Commission for Latin America and the Caribbean (ECLAC

www.cepal.org 